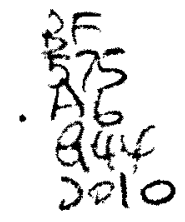

\title{
PERCEPTIONS OF ANXIETY SYMPTOMS AND DISCLOSURE OF ANXIETY BY OTHERS AMONG INDIVIDUALS WITH HIGH VERSUS LOW LEVELS OF SOCIAL ANXIETY \\ by
}

Bethany Gee

B.Sc., York University, 2007

\author{
A thesis \\ presented to Ryerson University \\ in partial fulfillment of the \\ requirements for the degree of \\ Master of Arts \\ in the Program of \\ Psychology
}

Toronto, Ontario, Canada, 2010

(C) Bethany Gee 2010 


\section{Author's Declaration}

I hereby declare that I am the sole author of this thesis.

I authorize Ryerson University to lend this thesis to other institutions or individuals for the purpose of scholarly research.

I further authorize Ryerson University to reproduce this thesis by photocopying or by other means, in total or in part, at the request of other institutions or individuals for the purpose of scholarly research.

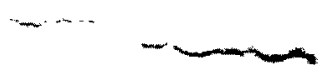




\begin{abstract}
Perceptions of Anxiety Symptoms and Disclosure of Anxiety by Others among Individuals with
\end{abstract} High versus Low Levels of Social Anxiety

Master of Arts, 2010

Bethany Gee

Psychology

Ryerson University

The present study investigated people's perceptions of anxiety symptoms and the disclosure of anxiety by others, and how one's own level of social anxiety affects these perceptions. Participants high $(n=80)$ and low $(n=83)$ in social anxiety were randomly assigned to watch one of four videos in which the target individual either appeared or did not appear anxious, and either disclosed or did not disclose her anxiety. Participants rated the target individual on various characteristics, and completed measures of their own level of social anxiety, perceived similarity to the target individual, and reasons for their ratings. Results indicated that participants negatively evaluated others who looked anxious on the qualities of awkward, socially skilled, and weak, and the disclosure of anxiety partially helped to decrease these negative judgements. Participants' own level of social anxiety did not affect the judgements. These findings may inform the process of cognitive restructuring. 


\section{Acknowledgements}

I would like to express gratitude to my supervisor, Dr. Martin M. Antony, and member of my supervisory committee, Dr. Naomi Koerner. Thank you very much for all of your time spent helping me throughout the thesis process, from the development of the idea through to the final thesis document. I would like to express my appreciation to Dr. Peter Farvolden, who generously agreed to serve on my examining committee. As well, I would like to thank my family, friends, and partner for their continuous encouragement and support. Finally, I would like to thank Audrey Aiken for her help with data collection, as well as Katie Fracalanza and Danielle Schwartz for their willingness to serve as actresses in my thesis videos. 


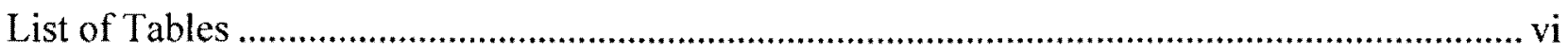

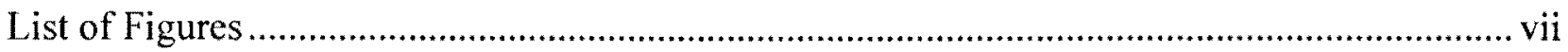

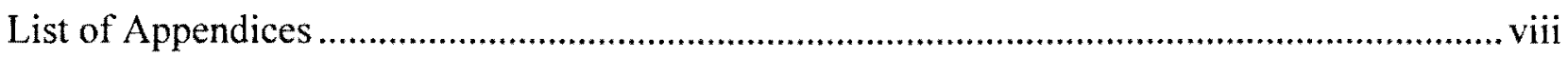

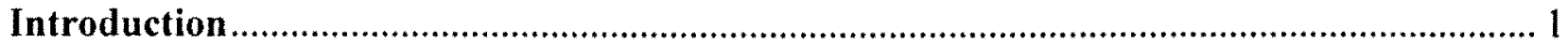

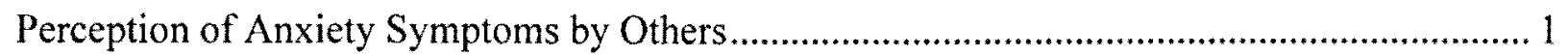

How Individuals High in Social Anxiety are Perceived ............................................................ 3

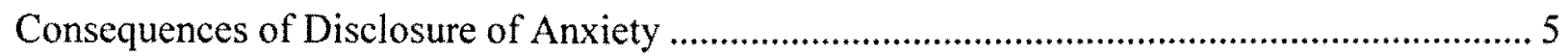

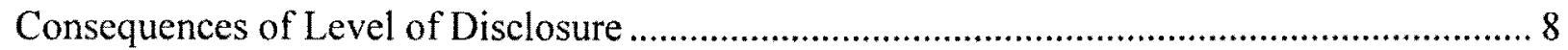

How Peoples' Level of Social Anxiety affects their Perceptions of Anxiety in Others ............. 9

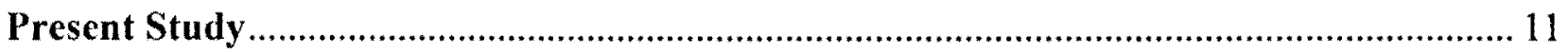

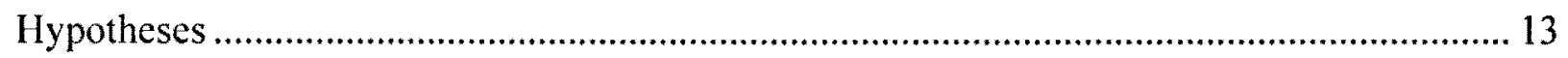

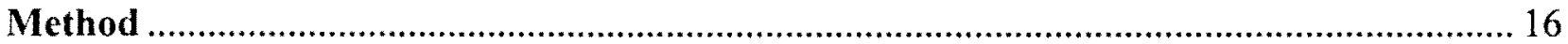

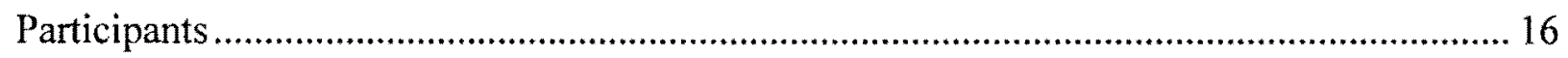

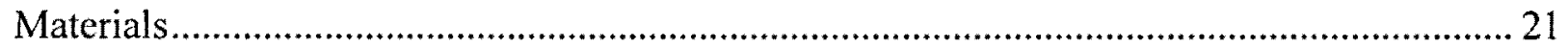

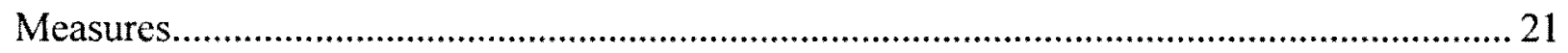

Procedure

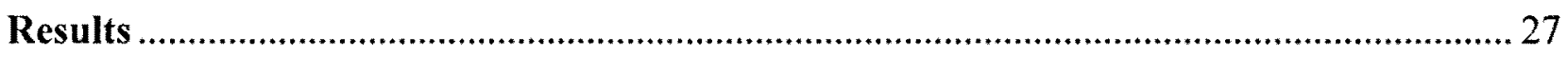

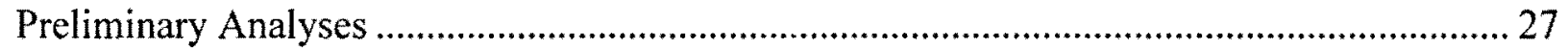

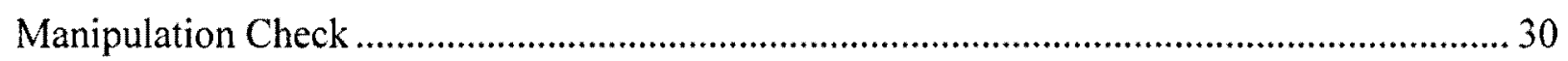

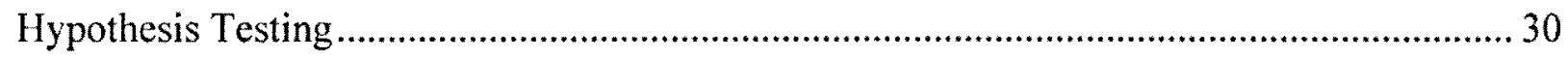

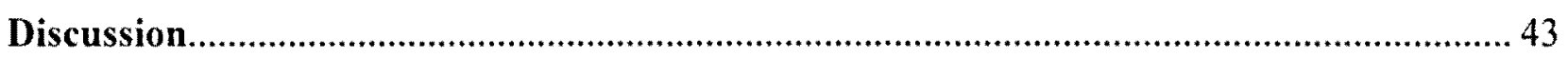

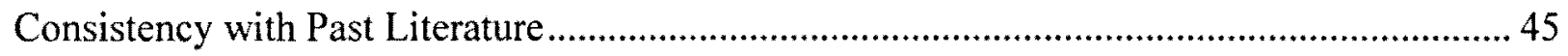

Theories Explaining the Negative Judgements of Others ...................................................... 47

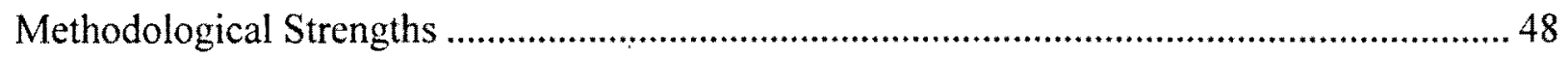

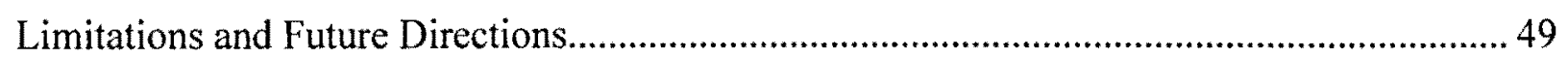

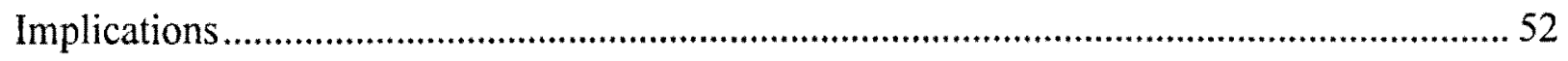

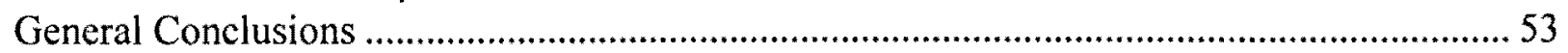

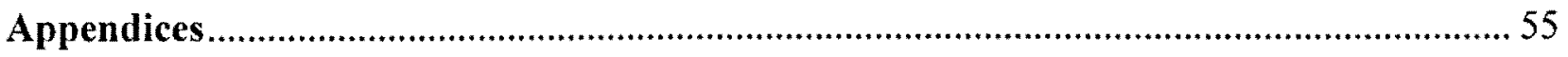

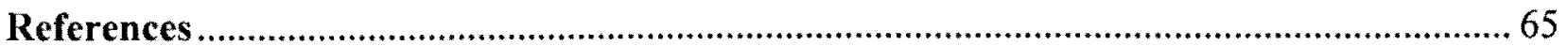




\section{List of Tables}

Table 1. Sample Characteristics separated by Video and Social Anxiety Conditions.................. 19

Table 2. Means and Standard Deviations of the SIAS, SPIN and MCSDS, separated by Video

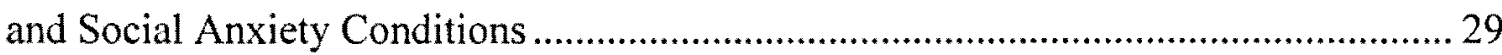

Table 3. Means and Standard Deviations of the Perception Rating Measure Variables for all Participants, separated by Video Condition.................................................................... 33

Table 4. Frequency of Participants Reporting Negative, Positive, or No Change in how Factors Affected their Ratings, separated by Video Condition.

Table 5. Correlations between Reasons for Ratings Measure and Perception Rating Measure, separated by Video Condition 


\section{List of Figures}

Figure 1. Ratings of target individual on "awkward" by video condition for participants low and

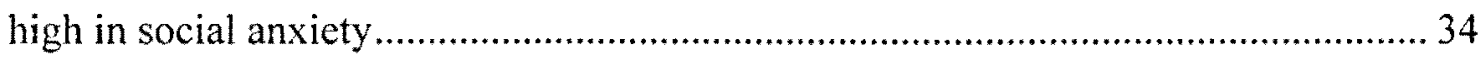

Figure 2. Ratings of target individual on "socially skilled" by video condition for participants

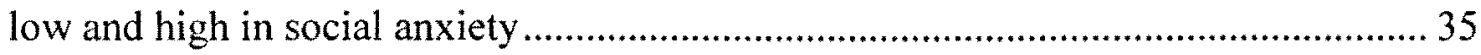

Figure 3. Ratings of target individual on "weak" by video condition for participants low and

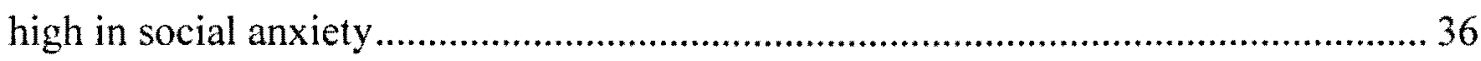

Figure 4. Ratings of target individual on "bored" by video condition for participants low and high in social anxiety 


\section{List of Appendices}

Appendix A: Perception Rating Measure 55

Appendix B: Reasons for Ratings Measure, 56

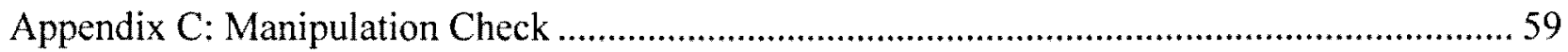

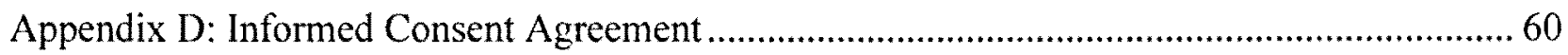

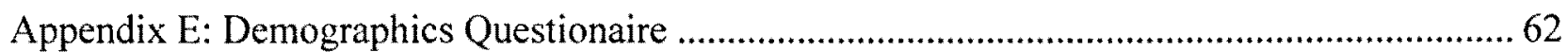

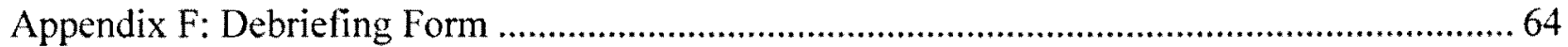


Perceptions of Anxiety Symptoms and Disclosure of Anxiety by Others among Individuals with High versus Low Levels of Social Anxiety

Social anxiety disorder is characterized by an intense fear of social or performance situations in which an individual might be embarrassed or humiliated. Exposure to the feared situation almost always triggers an anxiety response (e.g., sweating, tremors, blushing, muscle tension; American Psychiatric Association, 2000). Individuals with social anxiety disorder fear negative evaluation and many feel that their signs of anxiety are a primary contributor to this negative appraisal. They often report believing that their anxiety symptoms will be perceived by others as a sign of weakness, incompetence, and stupidity, and will lead to humiliation (Clark \& Wells, 1995; Scholing \& Emmelkamp, 1993). As well, they tend to overestimate the extent to which these signs of anxiety are apparent to others (Alden \& Wallace, 1995; Bruch, Borsky, Collins, \& Berger, 1989). Overemphasis on the importance of not showing anxiety symptoms often results in the individual being hypervigilant to any internal changes in bodily sensations, and results in further increases in anxiety.

\section{Perception of Anxiety Symptoms by Others}

Despite the common belief held by individuals with social anxiety disorder that their anxiety symptoms lead to negative evaluation from others, relatively little is known about how these symptoms are actually perceived by others. Purdon and colleagues (2001) conducted a study to examine this question, using an undergraduate sample. Participants completed a battery of social anxiety questionnaires, the Marlowe-Crowne Social Desirability Scale (MCSDS; Crowne \& Marlowe, 1960), and the Negative Evaluation Questionnaire (NEQ; Purdon, Antony, Monteiro, \& Swinson, 2001), which is a vignette task that asked participants to rate how their impression of an individual is affected when the individual appears anxious. Most participants in 
this study reported that anxiety symptoms in others would not influence their perception of the individual's intelligence, ambition, reliability, or mental health; however, at the same time, more than half of the participants reported they would think less of the individual's leadership abilities and strength of character. As well, participants high in social anxiety were more likely than participants lower in social anxiety to judge others who were displaying signs of anxiety as less attractive and as having less strength of character. The results of the study were limited by the relatively small sample size and the fact that data were based on self-report measures about a hypothetical situation, presented in written format.

A study by Papsdorf and Alden (1998) examined potential mediators of the relationship between social anxiety and social rejection. Female undergraduate participants of all levels of social anxiety engaged in a self-disclosure paradigm with a female confederate. The confederate and participant took turns talking about various topics from a list, though the confederate always spoke first and made an intimate disclosure. The participants were rated by the both the experimental confederate and a trained observer on: the extent of visible anxiety symptoms, the intimacy level of the self-disclosures, and perceived similarity between the participant and the confederate (both in general and on the dimensions of how they acted and talked). Following the interaction, the confederate also rated her willingness to engage in a future interaction with the participant, which presumably was related to likeability. Both the experimental confederate and trained observers were blind to the purpose of the study and hypotheses. It was found that participants who appeared overtly anxious were disliked by both the experimental confederate and trained observer slightly more than those who did not appear anxious. However, anxiety symptoms were not found to directly mediate the relationship between social anxiety and likeability; rather it served as an indicator of dissimilarity. That is, signs of anxiety did not 
directly lead to less likeability; rather, both the anxiety symptoms and less intimate disclosures indicated greater dissimilarity between the two conversation partners, which then led to less likeability. These findings suggest that individuals who appear anxious are not liked as much as those who do not appear anxious, because they may be perceived to be different, on the basis of their signs of anxiety and less intimate self-disclosures. However, it is important to note that the ratings of the participants by the confederate and observer may not be representative of the general population. Nonetheless, preliminary data would suggest that there is some negative evaluation in the perceptions of individuals who display signs of anxiety.

\section{How Individuals High in Social Anxiety are Perceived}

It has been found that individuals who are high in social anxiety, versus those who are low in social anxiety, are perceived more negatively by others. In first-time meeting situations, they are judged to be less attractive and less friendly (Jones \& Russell, 1982), more moody and lacking personal meaning in life (Creed \& Funder, 1998), and less likeable and less comfortable to be around (Meleshko \& Alden, 1993). They are viewed by their friends and families as less easy to talk to, less sympathetic, and less likable (e.g., Jones \& Carpenter, 1986). As mentioned previously, one explanation is that individuals who are socially anxious are rejected because they are seen to be different, because they show signs of anxiety and tend not to engage in reciprocal self-disclosure (Papsdorf \& Alden, 1998).

Another possible reason for these negative perceptions is that individuals who are high in social anxiety often use safety behaviours, which are cognitive and behavioural strategies designed to prevent feared events (i.e., negative evaluation) from occurring (Salkovskis, 1991). Some examples include wearing a turtleneck to hide flushing, gripping a glass tightly to conceal trembling, or mentally rehearsing a conversation to avoid stumbling over one's words. However, 
these behaviours can actually cause or exaggerate the feared symptoms (e.g., wearing a turtleneck can lead to increased flushing), and may result in even more negative perceptions of the individual (Alden \& Bieling, 1998). These negative reactions from others can in turn perpetuate the negative social expectations and behavioural avoidance of those high in social anxiety (Clark \& Well, 1995).

Another explanation for the negative perceptions of individuals who are high in social anxiety is that they may be less socially skilled. Studies have demonstrated that some individuals with social anxiety display poorer social skills, in comparison to those who are not socially anxious, as rated by independent observers (e.g., Baker \& Edelmann, 2002; Fydrich, Chambless, Perry, Buergener, \& Beazley, 1998). Alternatively, it is possible that the social behaviours of individuals high in social anxiety may produce negative emotions in others. Coyne (1976) found that after a 5 minute telephone conversation with an individual suffering from depression, participants reported being significantly more depressed, anxious, hostile, and rejecting. It has been proposed that this emotional contagion effect may also occur with individuals who have social anxiety, as depression and social anxiety share some similarities (Voncken et al., 2008).

Voncken and colleagues (2008) conducted a study with the purpose of determining which factors lead others to have negative perceptions towards socially anxious individuals. They proposed three factors that may play a role: i) social performance skills, ii) perceived similarity, and iii) elicited negative emotions. Participants with and without social anxiety disorder were observed during a 5 minute, first-meeting conversation with a confederate. The confederate and an observer then rated the participant on social performance, evoked negative emotions, perceived similarity, and social rejection (as measured by a scale assessing desire for future 
interaction). It was found that participants with social anxiety disorder displayed poorer social performance, which was associated with perceived dissimilarity. This relationship was mediated by evoked negative emotions, which together with perceived dissimilarity, was correlated with social rejection. Thus, a small number of studies have shed some light on the factors that may contribute to the negative perceptions of individuals with social anxiety. Continued research is needed to determine whether individuals with social anxiety disorder are perceived more negatively by others, and if so, reasons to explain this phenomenon.

\section{Consequences of Disclosure of Anxiety}

There is a vast literature on self-disclosure in general, including some research on selfdisclosure by people high in social anxiety in comparison to those low in social anxiety. However, an area of research that has seldom been explored is the self-disclosure of one's anxiety and its related consequences. To the author's knowledge, studies have not yet examined whether individuals high in social anxiety do in fact disclose their anxiety. However, it is possible that some socially anxious individuals may disclose their anxiety in order to try to prevent negative evaluation from others and decrease their own anxiety (i.e., they use disclosure as a safety behaviour). Other socially anxious individuals may do the opposite; that is, avoid disclosing their anxiety in an effort to feel more comfortable. It has not been well-established whether the self-disclosure of one's anxiety leads to more negative perceptions of the individual by others, as some safety behaviours have been found to do (e.g., rehearsing questions and answers in one's head during a conversation can lead to the individual being perceived as detached and unfriendly) (Alden, 2001; Clark, 2001).

The social psychological literature on self-disclosure has found a "liking effect," whereby those who self-disclose are generally liked more than those who do not disclose (see Collins \& 
Miller, 1994, for a review). However, it is important to note that some studies have found little or no relationship between self-disclosure and liking (Horenstein \& Gilbert, 1976; Kohen, 1975), and other studies have revealed a negative relationship under specific conditions, such as the disclosure of highly intimate content among acquaintances (Cozby, 1972; Dalto, Ajzen, \& Kaplan, 1979). Several studies have found that people who disclose negative information are liked less than those who disclose positive information (Dalto, Ajzen, \& Kaplan, 1979; Derlega, Harris, \& Chaikin, 1973). For example, Dalto and colleagues (1979) found that the disclosure of positive information, such as "I always try to be on time for appointments," leads to significantly greater attraction ratings, in comparison to the disclosure of negative information, such as "I can never remember the names of people I meet." However, as mentioned previously, it is not known whether the disclosure of anxiety would have similar effects as the disclosure of other types of negative information, although findings by Purdon and colleagues (2001) and Papsdorf and Alden (1998) suggest that this may be the case.

As mentioned previously, it has been postulated that one reason people are less likely to desire further interactions after an initial conversation with those who are high in social anxiety is because people high in social anxiety tend not to reciprocate self-disclosures (Alden \& Bieling, 1998; Meleshko \& Alden, 1993; Papsdorf \& Alden, 1998). It could thus be inferred that self-disclosure by those who are high in social anxiety may lead to more positive perceptions from others, depending on the content of the disclosure. However, it should be noted that some studies have not found that individuals with social anxiety disclose to a lesser extent, in comparison to those without social anxiety (Jacobson \& Anderson, 1982; Papsdorf \& Alden, 1998). 
To date, only one study has examined the social consequences of acknowledging and disclosing anxiety. Voncken, Alden and Bögels (2006) conducted a study investigating how individuals low and high in social anxiety perceive an individual who hides his or her anxiety, in comparison to an individual who discloses his or her anxiety. The participants included female undergraduate students who scored in the bottom and top quartile of the Social Interaction Anxiety Scale (SIAS; Mattick \& Clarke, 1998), and were consequently considered to be either low or high in social anxiety. They were presented with several written vignettes that depicted two colleagues interacting, with the target person either blushing, sweating, or trembling. The target person either: 1) acknowledged his or her anxiety (e.g., by saying "I feel a bit embarrassed and even start blushing...”, 2) concealed his or her anxiety (e.g., by turning a bit away and not making eye contact), or 3) neither acknowledged nor concealed his or her anxiety. Participants were instructed to predict how the colleague would perceive the target person, on a scale ranging from 0 (very negative) to 5 (very positive). It was found that all participants, regardless of their level of social anxiety, predicted that concealing anxiety would cause more negative perception ratings, in comparison to either acknowledging the anxiety, or neither acknowledging nor concealing the anxiety. No significant differences were found between ratings of those who acknowledged his or her anxiety, and those who neither acknowledged nor concealed his or her anxiety. Hence, the literature has found that displaying signs of anxiety can lead to some negative evaluation (i.e., poorer evaluation of leadership abilities and strength of character), but concealing anxiety may also result in poorer perception ratings.

Another study examined the effects of disclosures of various content on likeability ratings, including the disclosure of a feeling state. This doctoral dissertation by Stevick (1979) compared the effects of three different types of disclosures on the likeability ratings of an 
individual, using audiotapes. The study conditions included the disclosure of: 1) a failure (e.g., admitting self-perceived or other perceived defeats), 2) a feeling state (e.g., about one's frustrations or fear of failure), or 3) a non-personal message (e.g., factual information about a teaching experience). Stevick (1979) found that those who disclosed a failure were rated as less likable than those who disclosed a feeling or a non-personal message. Notably, no significant differences were found in ratings of likeability between individuals who disclosed a feeling, in comparison to those who disclosed a non-personal message. Therefore, the level of disclosure, specifically the intimacy of the disclosure, can have an impact on likeability ratings.

\section{Consequences of Level of Disclosure}

Cozby (1972) found a curvilinear relationship between disclosure and likeability, with the highest ratings of likeability occurring when the disclosure was of moderate intimacy, and the lowest ratings of likeability when the disclosure was of either extremely low intimacy or of extremely high intimacy. It was also found that those who made a high intimacy disclosure, in comparison to those who made a moderate intimacy disclosure, were rated as less honest, less intelligent, less discreet, and more anxious. It has been proposed by Collins and Miller (1994) that high levels of disclosure can be seen as inappropriate and violating social norms, in particular when the interaction is with strangers. Several researchers have found that unusually high levels of disclosure can cause psychological reactance (Brehm, 1966), which is defined as "a motivational state characterized by distress, anxiety, resistance, and the desire to restore [a behavioural freedom that has been lost]" (VandenBos, 2006). In relation to disclosure, psychological reactance can occur when an individual receives a highly intimate disclosure and feels a social pressure to reciprocate with an equally intimate disclosure (see Kleinke, 1979, for a review), and he or she then feels embarrassed and is uncertain of how to respond. 


\section{How People's Level of Social Anxiety affects their Perceptions of Anxiety in Others}

It has been found that individuals high in social anxiety evaluate their own behaviours more harshly and negatively (Clark \& Arkowitz, 1975; Rapee \& Lim, 1992), but judge other people's behaviours in the same way as people who are not anxious (Amir, Foa, \& Coles, 1998; Voncken, Alden, Bögels, 2006). For example, Amir and colleagues (1998) found that individuals with social anxiety disorder interpreted ambiguous social events more negatively when the scenarios were self-relevant, relative to when the scenarios were about others.

One theory of how people's level of social anxiety may influence their perceptions of anxiety in others can be deduced from the social psychology literature on similarity and attraction. This literature suggests that both actual and perceived similarity between individuals has an effect on attraction in laboratory studies, when individuals have a brief interaction. Both greater actual similarity and perceived similarity lead to higher attraction ratings, with perceived similarity having a larger effect (see Montoya, Horton, \& Kirchner, 2008, for a review). For example, mood congruence has been found to be associated with liking. Studies have showed that dysphoric and nondysphoric individuals report greater satisfaction with, and liking for, others whose mood matches their own (e.g., Rook, Pietromonaco, \& Lewis, 1994). From these studies, it can be inferred that those high in social anxiety would judge others who are displaying signs of anxiety as more similar to themselves, hence leading to higher attraction ratings.

However, it is important to note that at least one study has found that socially anxious individuals, in comparison to those who are less socially anxious, do in fact judge others who are displaying signs of anxiety more harshly. As mentioned previously, Purdon and colleagues (2001) found that more individuals high in social anxiety, versus those low in social anxiety, 
evaluated others who showed anxiety symptoms to have less strength of character and to be less attractive, in comparison to others who did not appear anxious.

In summary, although individuals with social anxiety disorder often fear being evaluated negatively due to their signs of anxiety, little is known regarding how anxiety symptoms are perceived by others. Preliminary studies suggest that there is some negative evaluation of others who show anxiety, and several reasons for these findings have been postulated. Since there is some evidence to show that people who are high in social anxiety are perceived more negatively by family members, friends, and strangers, it would be important to determine factors that contribute to these negative judgements in order to help improve these perceptions. Very little research has been conducted examining the social consequences of disclosing one's anxiety, however findings from the social psychology literature may help to predict and explain the consequences of the disclosure of anxiety. 


\section{Present Study}

The present study was conducted to assess people's perceptions of anxiety symptoms in others, people's perceptions of the disclosure of anxiety by others, and how a rater's own level of social anxiety affects his or her perceptions of others who appear anxious and disclose being anxious. The literature on the perceptions of others who display anxiety symptoms is sparse, and more research is needed to determine the relationship between social anxiety and interpersonal appraisals, as well as possible reasons for these judgements. The current study also aimed to avoid some of the limitations of previous studies, including using a study design that only allowed for the assessment of interpersonal appraisals using ratings by the confederate and observer (instead of a design that allowed for ratings by study participants), the use of written vignettes (which may not be sufficiently realistic), and the possibility of confounds when using confederates to interact with participants. The present study was designed to answer the following questions:

1. How are people perceived when they show signs of anxiety (and do not disclose their anxiety) compared to when they do not show signs of anxiety?

2. How are people perceived when they show signs of anxiety and disclose their anxiety at a low or high level compared to when they do not disclose their anxiety?

3. How does the rater's own level of social anxiety relate to his or her judgements of people who show signs of anxiety and/or disclose their anxiety?

4. Does the rater's perceived similarity on anxiety mediate the relationship between his or her own level of social anxiety and his or her judgements of people who show signs of anxiety and/or disclose their anxiety? 
The present study had a $2 \times 4$ factorial design. Participants who were either low or high in social anxiety were randomly assigned to watch one of the following: 1) a videotaped interaction between two women, including a target individual who did not display signs of anxiety and did not disclose feeling anxious, 2) a videotaped interaction between two women, including a target individual who displayed signs of anxiety and did not disclose feeling anxious, 3) a videotaped interaction between two women, including a target individual who displayed signs of anxiety and made a low level disclosure of anxiety, or 4) a videotaped interaction between two women, including a target individual who displayed signs of anxiety and made a high level disclosure of anxiety. Participants provided ratings of their perceptions of the target individual, including ratings on characteristics that people high in social anxiety tend to fear being labelled (e.g., awkward, weak), which served as the dependent variables.

As mentioned previously, the only other study examining the effects of acknowledging and disclosing anxiety is the study by Voncken, Alden and Bögels (2006). Their chosen methodology was to use written vignettes depicting conversations. These researchers suggested that future studies should examine this paradigm using either videotaped or actual social interactions, in order to increase the external validity. For the current study, videotape methodology was selected, as it provided a means to show conversations in a more realistic way than written vignettes. At the same time, it allowed for greater consistency of the conversations across participants, in comparison to using live social interactions.

For the current study, a low level disclosure of anxiety was operationalized as the target individual in the videotaped conversation stating, in the beginning to middle of the conversation, "I'm actually feeling a bit nervous talking to you right now. It's probably because we've just met." A high level disclosure of anxiety was operationalized as the target individual in the 
videotaped conversation stating, in the beginning to middle of the conversation, "I'm actually feeling really, really nervous talking to you right now. I'm an anxious person and I always feel anxious in social situations." The low level and high level disclosures therefore differed on the level of intimacy of the content, rather than on the quantity of the information being disclosed. As well, in the videotaped conversations, the target individual mainly asked her conversation partner questions and did not disclose much personal information about herself, with the exception of the disclosure of her anxiety in videos 3 and 4 .

\section{Hypotheses}

Four main hypotheses were tested in the present study.

Hypothesis 1. Based on the findings of Purdon and colleagues (2001) and Papsdorf and Alden (1998), it was hypothesized that the participants who watched the video in which the target individual appeared anxious would rate her more negatively than the participants who watched the video in which the target individual did not appear anxious, regardless of whether the target individual disclosed her anxiety, and regardless of the participant's own level of social anxiety.

Hypothesis $2 a$. Three competing hypotheses were proposed with regard to the disclosure of anxiety. First, it was possible that the individual who was visibly anxious and disclosed her anxiety, at either a low or high level, would be rated more positively by all participants, in comparison to the individual who was visibly anxious but did not disclose being anxious. This hypothesis is grounded in the finding that a lack of reciprocal self-disclosure makes others less likely to desire further interaction with those high in social anxiety after an initial conversation (Meleshko \& Alden, 1993). A second possibility was that the individual who was visibly anxious and disclosed her anxiety at a low or high level would be rated more negatively by all 
participants, in comparison to the individual who did not make a disclosure. This is based on the finding that people who disclose negative information about themselves are liked less than people who reveal positive information about themselves (Dalto, Ajzen, \& Kaplan, 1979; Derlega, Harris, \& Chaikin, 1973). Through the disclosure of anxiety, the target individual would be drawing attention to her anxiety, which some studies suggest can be viewed negatively by others (Papsdorf \& Alden, 1998; Purdon et al., 2001). A third possibility was that there would be no differences in the perceptions of the anxious individual who disclosed her anxiety, at either a low or high level, in comparison to the anxious individual who did not disclose her anxiety. This hypothesis was derived from the findings by Voncken and colleagues (2006), which did not find a significant difference between those who acknowledged their anxiety and those who neither acknowledged nor concealed their anxiety. It was also grounded in the findings by Stevick (1979), which did not find a significant difference in likeability ratings between those who disclosed a feeling, in comparison to those who disclosed a non-personal message.

Hypothesis 2b. Based on the findings of Cozby (1972), it was hypothesized that participants who viewed the video in which the target individual was visibly anxious and made a high disclosure of anxiety would rate her more negatively than participants who viewed the video in which the target individual was visibly anxious and made a low disclosure of anxiety, regardless of the participants' level of social anxiety.

Hypothesis 3. Two competing hypotheses were proposed with regard to how the rater's level of social anxiety would affect judgements. First, it was possible that participants who were high in social anxiety would rate the individual who displayed anxiety symptoms less negatively, in comparison to raters who were low in social anxiety. This is based on the literature on 
similarity and attraction, which suggests that both greater actual similarity and perceived similarity lead to higher attraction ratings (see Montoya, Horton, \& Kirchner, 2008, for a review). Second, it was possible that participants who were high in social anxiety would rate the individual who displayed anxiety symptoms more negatively, in comparison to raters who were low in social anxiety. This hypothesis was derived from the findings by Purdon and colleagues (2001) showing that more individuals high in social anxiety versus those low in social anxiety evaluated others who appear anxious to have less strength of character and to be less attractive, in comparison to others who did not appear anxious.

Hypothesis 4. Based on the similarity and attraction literature, as reviewed by Montoya, Horton, and Kirchner (2008), it was hypothesized that perceived similarity on anxiety would mediate the relationship between the participants' own level of social anxiety and their ratings of the target individual. 


\section{Method}

\section{Participants}

Undergraduate students enrolled in an Introduction to Psychology course at Ryerson University and individuals from the Greater Toronto Area community were recruited for participation in this study. The study was advertised as a "Thoughts about Everyday Conversations" study, with no mention of recruitment for low or high social anxiety. Ryerson University undergraduate students were recruited using SONA, which is an online participant recruitment software programme, and received partial course credit (1\%) for their participation. Through SONA, prescreening data were collected in both the fall and winter using mass-testing, which was open for 4 weeks in September and January. During fall and winter mass-testing, students ( $n=770$ and $n=692$, respectively) completed the Social Interaction Anxiety Scale (SIAS; Mattick \& Clarke, 1998), among other measures. The bottom and top quartiles of the total scores on the SIAS were used to establish cutoff scores for the low social anxiety group (score of 14 and below) and the high social anxiety group (score of 33 and above). These cutoff scores were then used to recruit undergraduate students and individuals from the community who were low $(n=80)$ or high $(n=83)$ in social anxiety.

Individuals from the community were recruited via advertisements posted at local universities and on the internet through free online classified advertisement websites, and were directed to complete an online version of the SIAS. If community participants were eligible for the study based on the pre-established cutoff scores, they were invited to the laboratory to participate in the study, for which they received compensation of 15 dollars. Establishing cutoff scores in the sample of undergraduate participants being used was deemed to be more accurate 
than using previously established cutoff scores from the literature, as no studies were found that used the SIAS with a community sample, nor with an undergraduate sample in Toronto.

The SIAS was also administered in the laboratory during the study and this SIAS score was used to categorize participants, versus the SIAS score obtained during prescreening, as discrepancies were found. A total of 213 participants who qualified for the study according to the SIAS prescreener were brought into the laboratory for study participation. Although data were collected for all 213 participants, only 163 of these participants qualified for the study according to the SIAS administered in the laboratory. Therefore, only the data from these 163 participants were used in the statistical analyses.

Of these 163 participants, 57 were from the community and 106 were Ryerson University undergraduate students recruited through SONA.' In the overall sample, $81.5 \%$ of participants were female and $18.5 \%$ were male. Participants ranged in age from 17 to 63 years $(M=24.03$, $S D=9.84$ ). The breakdown of self-identified ethnicity/cultural background was as follows: 48.8\% White/European, 30.7\% Asian, 9.2\% Black/Afro-Caribbean/African, 5.0\% Biracial/multiracial, $2.5 \%$ Hispanic/Latin American, and 3.6\% Other. The majority of participants reported being single (50.6\%), 35.8\% reported being in a steady relationship, $11.7 \%$ reported being married or cohabiting, and $1.8 \%$ reported being separated or divorced.

Participants reported the following educational levels: $47.9 \%$ completed some college/university, $27.6 \%$ completed high school/high school equivalency, $19.6 \%$ completed college/university, $2.5 \%$ completed some graduate school, $1.8 \%$ completed graduate school, and

\footnotetext{
1 The community and undergraduate samples differed significantly on the following variables: age (with the community sample being older), relationship status (with a greater percentage of the community sample being married, co-habiting, separated, or divorced, but a greater percentage of the undergraduate sample being in a steady relationship), current enrollment in an educational programme (with a greater percentage of the undergraduate sample being currently enrolled in an educational programme), and highest completed educational level (with the community sample having a higher level of completed education). However, since no significant differences between the two samples were found on social anxiety level, and all participants were randomized to the different video conditions, these variables were not used as covariates in the analyses.
} 
$0.6 \%$ did not attend high school. The majority of participants were working part-time $(52.4 \%)$ or not working (38.7\%), while $8.8 \%$ of participants were working full-time. Of the sample, $26.4 \%$ reported symptoms that met criteria for social anxiety disorder according to the DSM-IV-TR (American Psychiatric Association, 2000), as assessed by the Structured Clinical Interview for the DSM-IV (SCID-IV; First, Spitzer, Gibbon, \& Williams, 1996). Sample characteristics separated by video and social anxiety conditions are presented in Table 1.

Comparisons between the low and high social anxiety conditions revealed no significant differences on sex, relationship status, ethnicity, highest educational level attained, and employment. Independent $t$-tests revealed a significant difference between the low and high social anxiety conditions on age, $t(154)=3.17, p<.01$, with the low social anxiety group being older $(M=26.5, S D=12.3)$ than the high social anxiety group $(M=21.6, S D=5.8)$. However, age was not found to be significantly correlated with any of the dependent variables, and thus was not used as a covariate in the analyses. No significant differences were found between video conditions on demographic and clinical variables. 
Table 1

Sample Characteristics separated by Video and Social Anxiety Conditions

$\begin{array}{lllll}\text { Characteristic } & \text { Video } 1 & \text { Video } 2 & \text { Video } 3 & \text { Video } 4\end{array}$

\begin{tabular}{|c|c|c|c|c|c|c|c|c|}
\hline & $\begin{array}{c}\text { Low SA } \\
(n=20)\end{array}$ & $\begin{array}{c}\text { High SA } \\
(n=20)\end{array}$ & $\begin{array}{l}\text { Low SA } \\
(n=20)\end{array}$ & $\begin{array}{c}\text { High SA } \\
(n=21)\end{array}$ & $\begin{array}{c}\text { Low SA } \\
(n=20)\end{array}$ & $\begin{array}{c}\text { High SA } \\
(n=20)\end{array}$ & $\begin{array}{c}\begin{array}{c}\text { Low SA } \\
(n=20)\end{array} \\
\end{array}$ & $\begin{array}{c}\text { High SA } \\
(n=22)\end{array}$ \\
\hline Age $M(S D)$ & $\begin{array}{c}26.05 \\
(10.55)\end{array}$ & $\begin{array}{l}22.79 \\
(6.50)\end{array}$ & $\begin{array}{c}25.56 \\
(12.99)\end{array}$ & $\begin{array}{l}20.95 \\
(2.96)\end{array}$ & $\begin{array}{c}26.05 \\
(11.65)\end{array}$ & $\begin{array}{l}22.68 \\
(8.83)\end{array}$ & $\begin{array}{c}28.20 \\
(14.44)\end{array}$ & $\begin{array}{l}20.29 \\
(3.21)\end{array}$ \\
\hline $\begin{array}{l}\text { Gender (Frequency) } \\
\text { Male } \\
\text { Female }\end{array}$ & $\begin{array}{c}3(3.8 \%) \\
17(21.5 \%)\end{array}$ & $\begin{array}{c}4(4.8 \%) \\
16(19.3 \%)\end{array}$ & $\begin{array}{c}3(3.8 \%) \\
17(21.5 \%)\end{array}$ & $\begin{array}{c}6(7.2 \%) \\
15(18.1 \%)\end{array}$ & $\begin{array}{c}2(2.5 \%) \\
17(21.5 \%)\end{array}$ & $\begin{array}{c}3(3.6 \%) \\
17(20.5 \%)\end{array}$ & $\begin{array}{c}7(8.9 \%) \\
13(16.5 \%)\end{array}$ & $\begin{array}{c}2(2.4 \%) \\
20(24.1 \%)\end{array}$ \\
\hline $\begin{array}{l}\text { Race/Ethnicity (Frequency) } \\
\text { Aboriginal } \\
\text { Black/Afro-Caribbean/African } \\
\text { White/European } \\
\text { Hispanic/Latin American } \\
\text { Asian } \\
\text { Biracial/multiracial } \\
\text { Other }\end{array}$ & $\begin{array}{l}0(0.0 \%) \\
4(5.1 \%) \\
7(8.9 \%) \\
0(0.0 \%) \\
7(8.9 \%) \\
2(2.5 \%) \\
0(0.0 \%)\end{array}$ & $\begin{array}{c}0(0.0 \%) \\
2(2.4 \%) \\
11(13.4 \%) \\
0(0.0 \%) \\
6(7.3 \%) \\
1(1.2 \%) \\
0(0.0 \%)\end{array}$ & $\begin{array}{c}0(0.0 \%) \\
0(0.0 \%) \\
13(16.5 \%) \\
0(0.0 \%) \\
4(5.1 \%) \\
1(1.3 \%) \\
2(2.5 \%)\end{array}$ & $\begin{array}{l}0(0.0 \%) \\
2(2.4 \%) \\
9(11.0 \%) \\
1(1.2 \%) \\
6(7.3 \%) \\
0(0.0 \%) \\
2(2.4 \%)\end{array}$ & $\begin{array}{c}0(0.0 \%) \\
1(1.3 \%) \\
10(12.7 \%) \\
1(1.3 \%) \\
5(6.3 \%) \\
1(1.3 \%) \\
1(1.3 \%)\end{array}$ & $\begin{array}{c}0(0.0 \%) \\
2(2.4 \%) \\
10(12.2 \%) \\
0(0.0 \%) \\
7(8.5 \%) \\
1(1.2 \%) \\
0(0.0 \%)\end{array}$ & $\begin{array}{c}0(0.0 \%) \\
1(1.3 \%) \\
10(12.7 \%) \\
2(2.5 \%) \\
6(7.6 \%) \\
1(1.3 \%) \\
0(0.0 \%)\end{array}$ & $\begin{array}{l}0(0.0 \%) \\
3(3.7 \%) \\
8(9.8 \%) \\
0(0.0 \%) \\
9(11.0 \%) \\
1(1.2 \%) \\
1(1.2 \%)\end{array}$ \\
\hline $\begin{array}{l}\text { Education (Frequency) } \\
\text { Did not attend high school } \\
\text { Some high school } \\
\text { Completed high school/GED } \\
\text { Some college/university } \\
\text { Completed college/university } \\
\text { Some graduate school } \\
\text { Completed graduate school }\end{array}$ & $\begin{array}{c}0(0.0 \%) \\
0(0.0 \%) \\
5(5.0 \%) \\
11(13.8 \%) \\
4(5.0 \%) \\
1(1.2 \%) \\
0(0.0 \%)\end{array}$ & $\begin{array}{c}1(1.2 \%) \\
0(0.0 \%) \\
5(6.0 \%) \\
10(12.0 \%) \\
3(3.6 \%) \\
0(0.0 \%) \\
1(1.2 \%)\end{array}$ & $\begin{array}{c}0(0.0 \%) \\
0(0.0 \%) \\
5(8.8 \%) \\
10(12.5 \%) \\
2(2.5 \%) \\
1(1.2 \%) \\
0(0.0 \%)\end{array}$ & $\begin{array}{c}0(0.0 \%) \\
0(0.0 \%) \\
6(7.2 \%) \\
11(13.3 \%) \\
4(4.8 \%) \\
0(0.0 \%) \\
0(0.0 \%)\end{array}$ & $\begin{array}{l}0(0.0 \%) \\
0(0.0 \%) \\
5(5.0 \%) \\
9(11.2 \%) \\
6(7.5 \%) \\
1(1.2 \%) \\
0(0.0 \%)\end{array}$ & $\begin{array}{c}0(0.0 \%) \\
0(0.0 \%) \\
5(6.0 \%) \\
9(10.8 \%) \\
6(7.2 \%) \\
0(0.0 \%) \\
0(0.0 \%)\end{array}$ & $\begin{array}{l}0(0.0 \%) \\
0(0.0 \%) \\
5(7.5 \%) \\
6(7.5 \%) \\
5(6.2 \%) \\
1(1.2 \%) \\
2(2.5 \%)\end{array}$ & $\begin{array}{c}0(0.0 \%) \\
0(0.0 \%) \\
8(9.6 \%) \\
12(14.5 \%) \\
2(2.4 \%) \\
0(0.0 \%) \\
0(0.0 \%)\end{array}$ \\
\hline
\end{tabular}


Employment Status (Frequency)

Not working

Working part-time

Working full-time

Relationship Status (Frequency)

Single
In a steady relationship
Married
Co-habiting
Separated
Divorced
Widowed

$\begin{array}{cccccccc}5(6.3 \%) & 7(8.6 \%) & 11(13.9 \%) & 9(11.1 \%) & 4(5.1 \%) & 8(9.9 \%) & 9(11.4 \%) & 9(11.1 \%) \\ 11(13.9 \%) & 11(13.6 \%) & 8(10.1 \%) & 11(13.6 \%) & 13(16.5 \%) & 9(11.1 \%) & 10(12.7 \%) & 11(13.6 \%) \\ 3(3.8 \%) & 1(1.2 \%) & 1(1.3 \%) & 1(1.2 \%) & 3(3.8 \%) & 3(3.7 \%) & 1(1.3 \%) & 1(1.2 \%) \\ & & & & & & & \\ 10(12.7 \%) & 9(10.8 \%) & 13(16.5 \%) & 11(13.3 \%) & 9(11.4 \%) & 8(9.6 \%) & 10(12.7 \%) & 12(14.5 \%) \\ 8(10.1 \%) & 10(12.0 \%) & 4(5.1 \%) & 7(8.4 \%) & 5(6.3 \%) & 9(10.8 \%) & 6(7.6 \%) & 9(10.8 \%) \\ 1(1.3 \%) & 1(1.2 \%) & 1(1.3 \%) & 2(2.4 \%) & 3(3.8 \%) & 0(0.0 \%) & 4(5.1 \%) & 0(0.0 \%) \\ 1(1.3 \%) & 0(0.0 \%) & 1(1.3 \%) & 1(1.2 \%) & 1(1.3 \%) & 2(2.4 \%) & 0(0.0 \%) & 1(1.2 \%) \\ 0(0.0 \%) & 0(0.0 \%) & 1(1.3 \%) & 0(0.0 \%) & 1(1.3 \%) & 0(0.0 \%) & 0(0.0 \%) & 0(0.0 \%) \\ 0(0.0 \%) & 0(0.0 \%) & 0(0.0 \%) & 0(0.0 \%) & 0(0.0 \%) & 1(1.2 \%) & 0(0.0 \%) & 0(0.0 \%) \\ 0(0.0 \%) & 0(0.0 \%) & 0(0.0 \%) & 0(0.0 \%) & 0(0.0 \%) & 0(0.0 \%) & 0(0.0 \%) & 0(0.0 \%) \\ 0(0.0 \%) & 12(7.4 \%) & 0(0.0 \%) & 14(8.6 \%) & 0(0.0 \%) & 8(4.9 \%) & 0(0.0 \%) & 9(5.5 \%)\end{array}$

Social Anxiety Disorder

(Frequency) $^{\mathrm{a}}$

Note. SA=Social Anxiety

Note. Numbers in each column may not add up to the total number of participants in each condition due to a small amount of missing data on the demographics questionnaire. 


\section{Materials}

Videos. Four videos were created depicting two women in their twenties having a conversation about their summer vacations in a first-time meeting situation, for approximately 2 minutes. In each video, one individual did not display any anxiety symptoms and did not disclose any information about whether she was experiencing anxiety. The other individual (the target individual) behaved differently with respect to her anxiety in each of the four videos. In video 1 , the target individual did not display any anxiety symptoms and did not disclose information about whether she was experiencing anxiety. In video 2 , the target individual displayed anxiety symptoms (i.e., avoided eye contact, fidgeted, and spoke in a higher, more tentative voice), but did not disclose information about whether she was experiencing anxiety. In video 3 , the target individual displayed anxiety symptoms (i.e., avoided eye contact, fidgeted, and spoke in a higher, more tentative voice), and engaged in a low level disclosure about her anxiety. In video 4, the target individual displayed anxiety symptoms (i.e., avoided eye contact, fidgeted, and spoke in a higher, more tentative voice), and engaged in a high level disclosure about her anxiety. All other aspects of the videos were identical.

\section{Measures}

Perception Rating Measure (PRM; designed for use in this study). The PRM was used to obtain ratings of the target individual in the videotaped conversation on the descriptors of: intelligent, worthless, interesting, awkward, socially skilled, weak, attractive, and bored (see Appendix A). These descriptors, among others, were elicited from an expert panel consisting of a psychiatrist, psychologists, and graduate students from Ryerson University (Toronto, $\mathrm{ON}$ ) and the Anxiety Treatment and Research Centre (Hamilton, ON), who had experience assessing or treating individuals with social anxiety disorder. They suggested these characteristics as ones on 
which people with social anxiety disorder often worry about being judged. The study team reviewed all of the suggested descriptors and selected those that were most relevant, based on consensus. Responses to the PRM were made on a 5-point Likert scale, with answers ranging from 0 (not at all) to 4 (extremely). Scores from the individual items of the PRM served as the dependent variables of interest.

Social Interaction Anxiety Scale (SIAS; Mattick \& Clarke, 1998). The SIAS is a 20item, self-report measure that assesses anxiety, specific to social interactions. Examples of items include: "I have difficulty talking with other people," "I find it difficult to disagree with another's point of view," and "When mixing in a group, I find myself worrying I will be ignored." Responses are made on a 5-point Likert scale, with answers ranging from 0 (not at all) to 4 (extremely). The SIAS has strong internal consistency and can discriminate individuals with social anxiety from those with other anxiety disorders (Brown, Turovsky, Heimberg, Juster, Brown, \& Barlow, 1997; Mattick \& Clarke, 1998). This measure was used to classify participants as low or high in social anxiety. Cutoff scores for low and high social anxiety were based upon the bottom and top quartile of total scores on the SIAS, respectively, during SONA mass-testing. The cutoff scores were found to be 14 and below for the low social anxiety condition, and 33 and above for the high social anxiety condition. The SIAS was also administered during the study and these scores were used to categorize participants, versus the SIAS scores obtained during mass testing, since discrepancies were found.

Social Phobia Inventory (SPIN; Connor et al., 2000). The SPIN was administered to measure the participants' level of social anxiety in the past week, across a variety of situations, including social interactions, displaying anxiety symptoms, and fear of criticism. It is a 17 -item, self-report measure in which participants record the extent to which they fear various social 
situations on a 5-point Likert scale, with answers ranging from 0 (not at all) to 4 (extremely). The SPIN has demonstrated good validity and reliability (Antony, Coons, McCabe, Ashbaugh, \& Swinson, 2006; Connor et al., 2000). This measure was used to assess whether individuals whose symptoms met DSM-IV-TR criteria for social anxiety disorder had similar levels of social anxiety as those in the high social anxiety condition whose symptoms did not meet these criteria.

\section{Structured Clinical Interview for DSM-IV (SCID-IV; First, Spitzer, Gibbon, \&}

Williams, 1996). The social phobia section of the SCID-IV was administered to determine whether participants' symptoms met criteria for a diagnosis of social anxiety disorder. The SCID-IV is a semistructured diagnostic interview that assesses the DSM-IV-TR criteria for various psychological disorders, including social anxiety disorder. The reliability of a social anxiety disorder diagnosis using the SCID-IV has been found to be satisfactory (Del-Ben et al., 2005). The version of the SCID used in this study was modified such that participants provided ratings of their anxiety for a wide range of social situations (in addition to the few that are asked about in the SCID). The social phobia section of the SCID-IV was administered by the experimenter or a trained research assistant.

Short form of the Marlowe-Crowne Social Desirability Scale (Reynolds, 1982). This measure was administered to assess prosocial response biases that may have affected perception ratings. It is a 13-item self-report measure and includes items that are culturally acceptable behaviours that are low in likelihood. Participants answer each question with a true or false response, and those who score highly on this measure are interpreted as having a higher prosocial response bias. The short form of the Marlowe-Crowne Social Desirability Scale has demonstrated acceptable levels of validity and reliability, and is comparable to the original version on both reliability and validity (Reynolds, 1982). It is thus recommended as a viable 
measurement for use in the assessment of social desirability response bias (Reynolds, 1982; Zook li \& Sipps, 1985). This measure was included in order to assess whether social desirability scores were correlated with perception ratings, and if this was found to be the case, social desirability would be used as a covariate in the analyses.

Reasons for Ratings Measure (RRM; designed for use in this study). The RRM consists of questions about factors that may have influenced participants' ratings of the target individual in the videotaped conversations (see Appendix B). The measure asked to what extent the participant's ratings were influenced by the target individual's body language, signs of anxiety, and statement that she felt nervous (if applicable). Filler questions were included so that the purpose of the study was not readily apparent. Responses were made on a 5-point Likert scale, with answers ranging from 1 (factor X made me think much more negatively of her) to 3 (factor X had no effect on my rating) to 5 (factor X made me think much more positively of her). If participants did not notice factor X, they were asked to give a response of "3." Participants were also asked to indicate which two variables had the most influence on their ratings of the target individual. This questionnaire was included to determine which variables participants thought had the most influence on their ratings.

In order to assess level of perceived similarity, participants were asked, "How similar are you to the person in the video on your left (who was wearing the grey t-shirt) in terms of your level of anxiety in social situations?" and "In social situations, do you think you are more or less anxious than the individual in the video on your left (who was wearing the grey t-shirt)?" These questions were included in order to assess whether perceived similarity mediated the relationship between participant level of social anxiety and their ratings of the target individual. 
Manipulation Check (designed for use in this study). A manipulation check was included to assess how well participants were able to follow the instructions for watching the videotaped interactions, the believability of the interactions, as well as how anxious they viewed the target individual. Participants rated the degree to which: 1) they were able to imagine themselves in the shoes of the person speaking to the target individual, 2) they were able to imagine themselves engaging in a conversation with the target individual, 3) the videotaped conversation seemed realistic, and 4) the target individual appeared anxious (see Appendix C). Responses were made on a 5-point Likert scale, with answers ranging from 0 (not at all) to 4 (extremely). Filler questions were included so that the purpose of the study was not readily apparent.

\section{Procedure}

Participants were run individually. Upon arrival, participants read and signed an informed consent agreement (see Appendix D) and completed a demographics questionnaire (see Appendix E). The following instructions were given: "This is a video of two students acting out an everyday conversation. Imagine that you are the person on the right (experimenter points to the individual on the right), talking to the person on the left, who is wearing a grey t-shirt (experimenter points to the individual on the left). You will then be making ratings about the person on the left (experimenter points to the individual on the left), so please pay more attention to her while you are watching the video. Once again, please imagine you are the individual on the right (experimenter points to the individual on the right), having a conversation with the person on the left (experimenter points to the individual on the left)." The participant was then shown one of the four videos. 
After viewing the video, the participant completed the Perception Rating Measure, Reasons for Ratings Measure, and Manipulation Check. Next, the participant completed the short form of the Marlowe-Crowne Social Desirability Scale (Reynolds, 1985), Social Interaction Anxiety Scale (SIAS; Mattick \& Clarke, 1998), Social Phobia Inventory (SPIN; Connor et al., 2000), as well as other measures as part of another study. The experimenter or research assistant then administered the social phobia section of the Structured Clinical Interview for DSM-IV (SCID-IV; First, Spitzer, Gibbon, \& Williams, 1996). Participants were then asked questions to see if they had knowledge about the hypotheses of the study, provided with a verbal debriefing and written debriefing form (see Appendix F), and provided with an opportunity to ask questions. 


\section{Results}

\section{Preliminary Analyses}

The main variables of interest were tested for the presence of outliers and normality of distribution, and it was found that these variables were within an acceptable range and approximated a normal distribution. Mean scores and standard deviations on the SIAS, SPIN, and MCSDS, separated by video and social anxiety conditions, are presented in Table 2 . As expected, comparisons between the low and high social anxiety conditions revealed significant differences on the SIAS, $t(161)=5.75, p<.001$, and the SPIN, $t(161)=37.79, p<.001$, with participants in the high social anxiety condition producing much higher scores on both measures. The SIAS scores of the participants in the high social anxiety condition in the current study $(M=46.0, S D=8.3$ ) were higher than those of the social anxiety disorder sample used by Mattick and Clark (1998; $M=34.6, S D=16.4)$, and slightly lower than those found in the social anxiety disorder sample used by Heimberg and colleagues (1992; $M=49.0, S D=15.6)$. Scores on the MCSDS were also significantly different, $t(160)=20.61, p<.001$, with the low social anxiety condition scoring higher on social desirability than the high social anxiety condition. However, scores of the MCSDS were not found to be correlated with scores on the Perception Rating Measure, and hence were not used as a covariate in the analyses.

Upon examination of the individuals in the high social anxiety condition, significant differences were found on SIAS and SPIN scores among individuals whose symptoms did and did not meet criteria for social anxiety disorder, according to the DSM-IV-TR: SIAS, $t(81)=$ $2.67, p<.01 ;$ SPIN, $t(80)=3.33, p<.01$. Participants with social anxiety disorder had significantly higher scores on both the SIAS $(M=48.28, S D=8.32)$ and SPIN $(M=34.84$, $S D=9.05$ ), in comparison to individuals in the high social anxiety condition whose symptoms did 
not meet criteria for social anxiety disorder (SIAS, $M=43.60, S D=7.63 ; \mathrm{SPIN}, M=28.21$, $S D=8.97)$. 
Table 2

Means and Standard Deviations of the SIAS, SPIN and MCSDS, separated by Video and Social Anxiety Conditions

\begin{tabular}{lcccccccc} 
Measure & \multicolumn{3}{c}{ Video 1 } & \multicolumn{2}{c}{ Video 2 } & \multicolumn{2}{c}{ Video 3 } & \multicolumn{2}{c}{ Video 4 } \\
\cline { 2 - 9 } & $\begin{array}{c}\text { Low SA } \\
(n=20)\end{array}$ & $\begin{array}{c}\text { High SA } \\
(n=20)\end{array}$ & $\begin{array}{c}\text { Low SA } \\
(n=20)\end{array}$ & $\begin{array}{c}\text { High SA } \\
(n=21)\end{array}$ & $\begin{array}{c}\text { Low SA } \\
(n=20)\end{array}$ & $\begin{array}{c}\text { High SA } \\
(n=20)\end{array}$ & $\begin{array}{c}\text { Low SA } \\
(n=20)\end{array}$ & $\begin{array}{c}\text { High SA } \\
(n=22)\end{array}$ \\
\hline SIAS & $7.65(3.90)$ & $43.95(6.07)$ & $8.57(3.18)$ & $46.24(9.93)$ & $8.80(4.18)$ & $46.00(9.66)$ & $6.83(4.12)$ & $47.73(7.02)$ \\
SPIN & $6.12(4.78)$ & $29.05(10.46)$ & $6.55(4.01)$ & $34.01(8.78)$ & $8.83(6.78)$ & $30.57(10.32)$ & $6.62(3.66)$ & $32.62(8.54)$ \\
MCSDS & $3.04(1.59)$ & $2.36(1.56)$ & $3.49(1.09)$ & $1.71(1.19)$ & $3.03(1.26)$ & $2.52(1.43)$ & $3.17(1.21)$ & $1.36(1.14)$ \\
\hline
\end{tabular}

Note. SA = Social anxiety; SIAS = Social Interaction Anxiety Scale; SPIN = Social Phobia Inventory; MCSDS = Marlowe-Crowne Social Desirability Scale Note. Video 1 - target individual does not appear anxious (and does not disclose her anxiety),

Video 2 - target individual appears anxious and does not disclose her anxiety,

Video 3 - target individual appears anxious and discloses her anxiety at a low level,

Video 4 - target individual appears anxious and discloses her anxiety at a high level. 


\section{Manipulation Check}

The majority $(92.6 \%)$ of participants were able to follow the instructions to imagine themselves as the person in the video on the right, as if they were engaging in a conversation with the person in the video on the left. However, four participants (two male and two female) indicated that they were "not at all" able to imagine being the individual in the video on the right, nor imagine engaging in a conversation with the individual in the video on the left. Almost all participants $(97.5 \%)$ indicated that the videotaped conversation seemed realistic.

Of the participants who watched the video in which the target individual did not display signs of anxiety, the largest percentage (37.5\%) indicated that the target individual appeared " $a$ little bit" nervous. Other participants rated the extent of her nervousness as: 17.5\% "not at all," $22.5 \%$ "somewhat," $17.5 \%$ "very much," and 5\% "extremely." Of the participants who watched the video in which the target individual displayed signs of anxiety, most indicated that the target individual appeared "very much" or "extremely" nervous (31.7\% and 59.3\%, respectively). Other participants rated the extent of her nervousness as: $0.8 \%$ "not at all," $2.4 \%$ "a little bit," and $5.7 \%$ "somewhat."

\section{Hypothesis Testing}

To test Hypotheses 1 through 3, a 2 (participant: low social anxiety versus high social anxiety) $x 4$ (video: no anxiety symptoms and no disclosure, versus anxiety symptoms and no disclosure, versus anxiety symptoms and low disclosure, versus anxiety symptoms and high disclosure) analyses of variance (ANOVA) was performed on the dependent variables. Table 3 presents the means and standard deviations of the dependent variables for all participants, separated by video condition. 
Analyses indicated a significant main effect of video condition on the following variables: awkward, $F(3,155)=34.51, p<.001$, socially skilled, $F(3,154)=13.10, p<.001$, weak, $F(3,152)=4.92, p<.01$, and bored, $F(3,154)=5.30, p<.01 .^{2}$ No significant main effects were found on ratings of intelligent, worthless, interesting, or attractive. To test Hypothesis 1, Bonferroni adjusted pairwise comparisons were conducted and revealed that participants who watched video 1, in which the target individual appeared anxious (versus the participants who watched video 2 , in which she did not appear anxious), judged her to be 1.8 points more awkward, $F(3,155)=34.51, p<.001, d=1.67, .95$ points less socially skilled, $F(3,154)=13.10$, $p<.001, d=-1.06$, and .88 points more weak, $F(3,152)=4.92, p<.01, d=.77$.

Disclosure appeared to play a role in the ratings of weak and bored, but not in the ratings of any other characteristics. Participants who watched the video in which the target individual appeared anxious and made a low level disclosure of her anxiety (video 3 ) rated her as .78 points more weak, in comparison to participants who watched the video in which the target individual did not appear anxious (and did not disclose anxiety; video 1). However, participants who watched the video in which the target individual appeared anxious and made a high level disclosure of her anxiety (video 4) did not rate her more negatively than participants who watched the video in which the target individual did not appear anxious (and did not disclose anxiety; video 1). Thus, showing anxiety symptoms and disclosing at a high level did not lead to the negative ratings on the characteristic of "weak" that were found when an individual appeared anxious and either did not disclose her anxiety or disclosed it at a low level. As well, when participants watched the video in which the target individual appeared anxious and disclosed at a low or high level (video 3 or 4), they rated her as .68 and .89 points less bored, respectively, in

\footnotetext{
${ }^{2}$ Degrees of freedom are not consistent across analyses due to a small amount of missing data on the Perception Rating Measure.
} 
comparison to participants who watched the video in which the target individual appeared anxious but did not disclose her anxiety (video 2). Therefore, when an individual appeared anxious and disclosed her anxiety at a low or high level, others did not rate her as appearing as bored as they did for an individual who showed signs of anxiety but did not disclose her anxiety. No significant differences were found on ratings of "bored" when the target individual appeared anxious and disclosed at a low level (video 3 ) compared to when she appeared anxious and disclosed at a high level (video 4). Additionally, no significant main effects of social anxiety were found. Finally, no significant interactions between video condition and social anxiety condition were found. Ratings of the target individual on "awkward," "socially skilled," "weak," and "bored" separated by video condition for participants low and high in social anxiety are displayed in figures 1 to 4 . 
Table 3

Means and Standard Deviations of Perception Rating Measure Variables for all Participants, separated by Video Condition

Characteristic Video $1(n=40) \quad$ Video $2(n=41) \quad$ Video $3(n=40) \quad$ Video $4(n=42)$

\begin{tabular}{lcccccccc} 
& $M$ & $S D$ & $M$ & $S D$ & $M$ & $S D$ & $M$ & $S D$ \\
\hline Awkward & $1.20^{\mathrm{a}}$ & .97 & $2.98^{\mathrm{b}}$ & 1.17 & $3.20^{\mathrm{b}}$ & .91 & $3.00^{\mathrm{b}}$ & .96 \\
Socially skilled & $2.20^{\mathrm{a}}$ & .94 & $1.25^{\mathrm{b}}$ & .87 & $1.20^{\mathrm{b}}$ & .61 & $1.33^{\mathrm{b}}$ & .82 \\
Weak & $.90^{\mathrm{a}}$ & 1.05 & $1.77^{\mathrm{b}}$ & 1.21 & $1.68^{\mathrm{b}}$ & 1.00 & $1.34^{\mathrm{a} . \mathrm{b}}$ & 1.24 \\
Bored & $1.05^{\mathrm{a}, \mathrm{b}}$ & .93 & $1.59^{\mathrm{a}, \mathrm{b}}$ & 1.20 & $.90^{\mathrm{a}, \mathrm{c}}$ & 1.08 & $.68^{\mathrm{a}, \mathrm{c}}$ & .96 \\
Intelligent & $1.93^{\mathrm{a}}$ & .53 & $1.90^{\mathrm{a}}$ & .82 & $1.92^{\mathrm{a}}$ & .53 & $2.10^{\mathrm{a}}$ & .63 \\
Worthless & $.41^{\mathrm{a}}$ & .85 & $.80^{\mathrm{a}}$ & .94 & $.65^{\mathrm{a}}$ & .98 & $.38^{\mathrm{a}}$ & .70 \\
Interesting & $1.45^{\mathrm{a}}$ & 1.06 & $1.17^{\mathrm{a}}$ & 1.05 & $1.35^{\mathrm{a}}$ & 1.03 & $1.43^{\mathrm{a}}$ & 1.13 \\
Attractive & $2.25^{\mathrm{a}}$ & .93 & $1.88^{\mathrm{a}}$ & .88 & $2.15^{\mathrm{a}}$ & .89 & $2.13^{\mathrm{a}}$ & .62 \\
\hline
\end{tabular}

8.b Means sharing superscripts across rows do not differ significantly at $p<.05$, according to Bonferroni pairwise comparisons.

Note. Video 1 - target individual does not appear anxious (and does not disclose her anxiety),

Video 2 - target individual appears anxious and does not disclose her anxiety,

Video 3 -target individual appears anxious and discloses her anxiety at a low level,

Video 4 - target individual appears anxious and discloses her anxiety at a high level. 


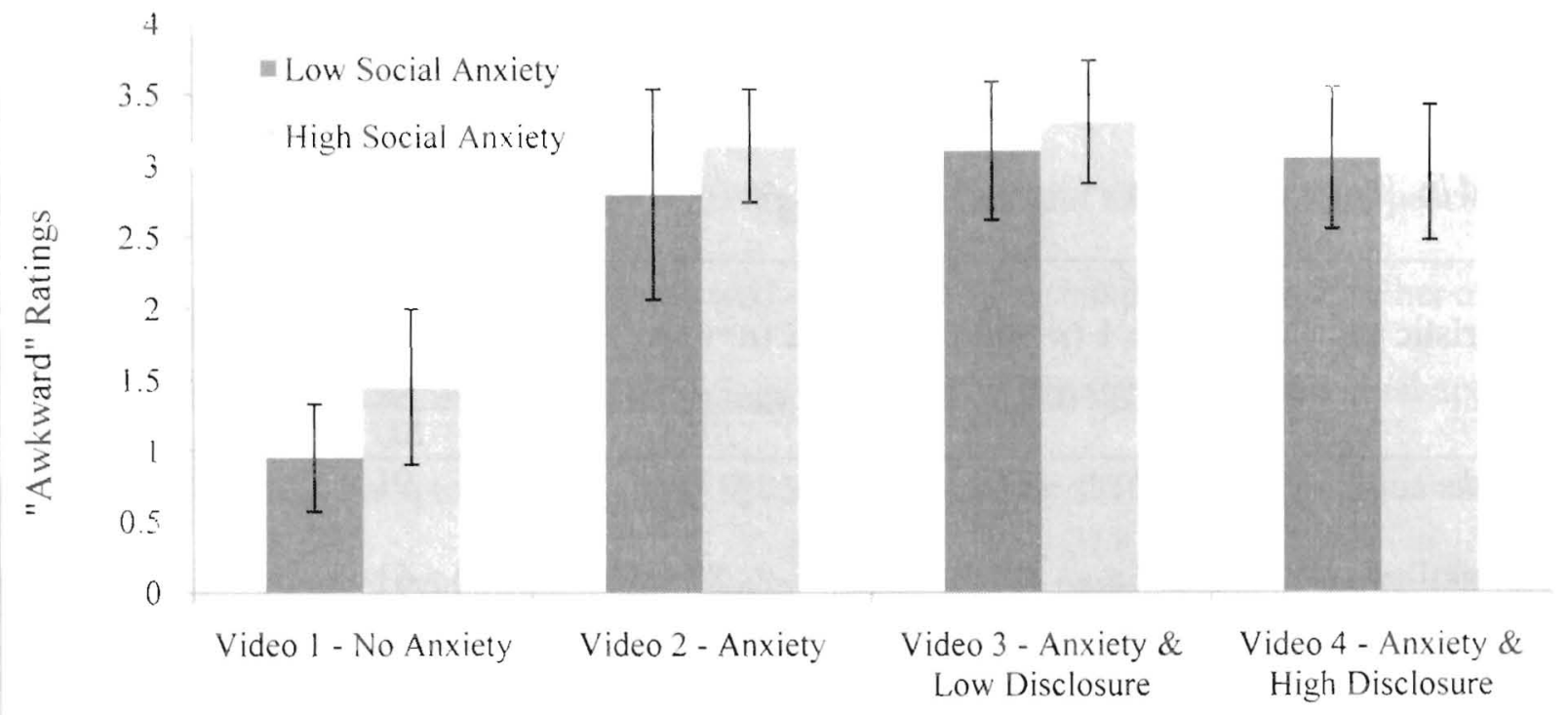

Video Condition

Figure 1. Ratings of target individual on "awkward" by video condition for participants low and high in social anxiety. Standard errors are represented in the figure by the error bars attached to each data point. 


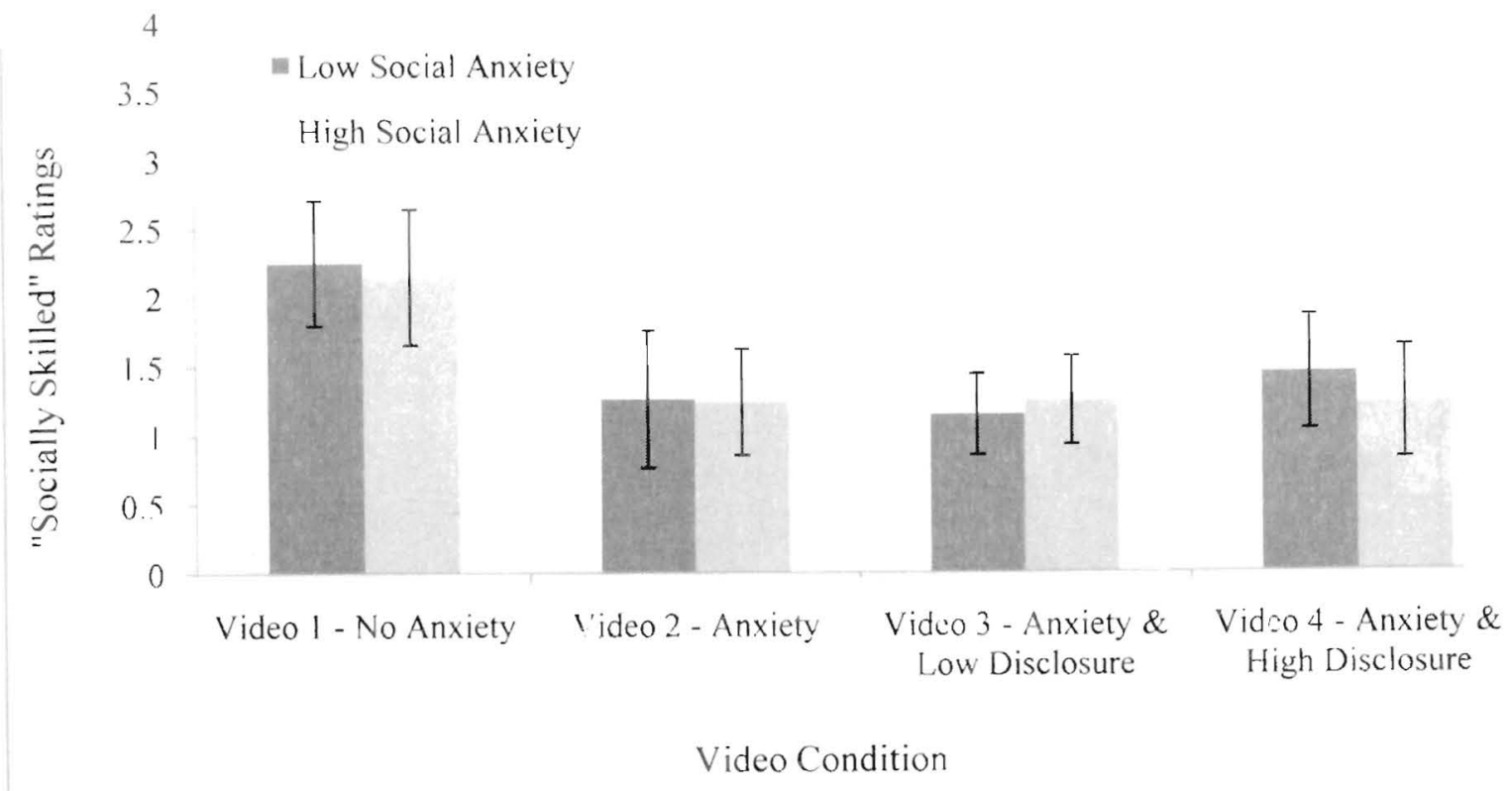

Figure 2. Ratings of target individual on "socially skilled" by video condition for participants low and high in social anxiety. Standard errors are represented in the figure by the error bars attached to each data point. 


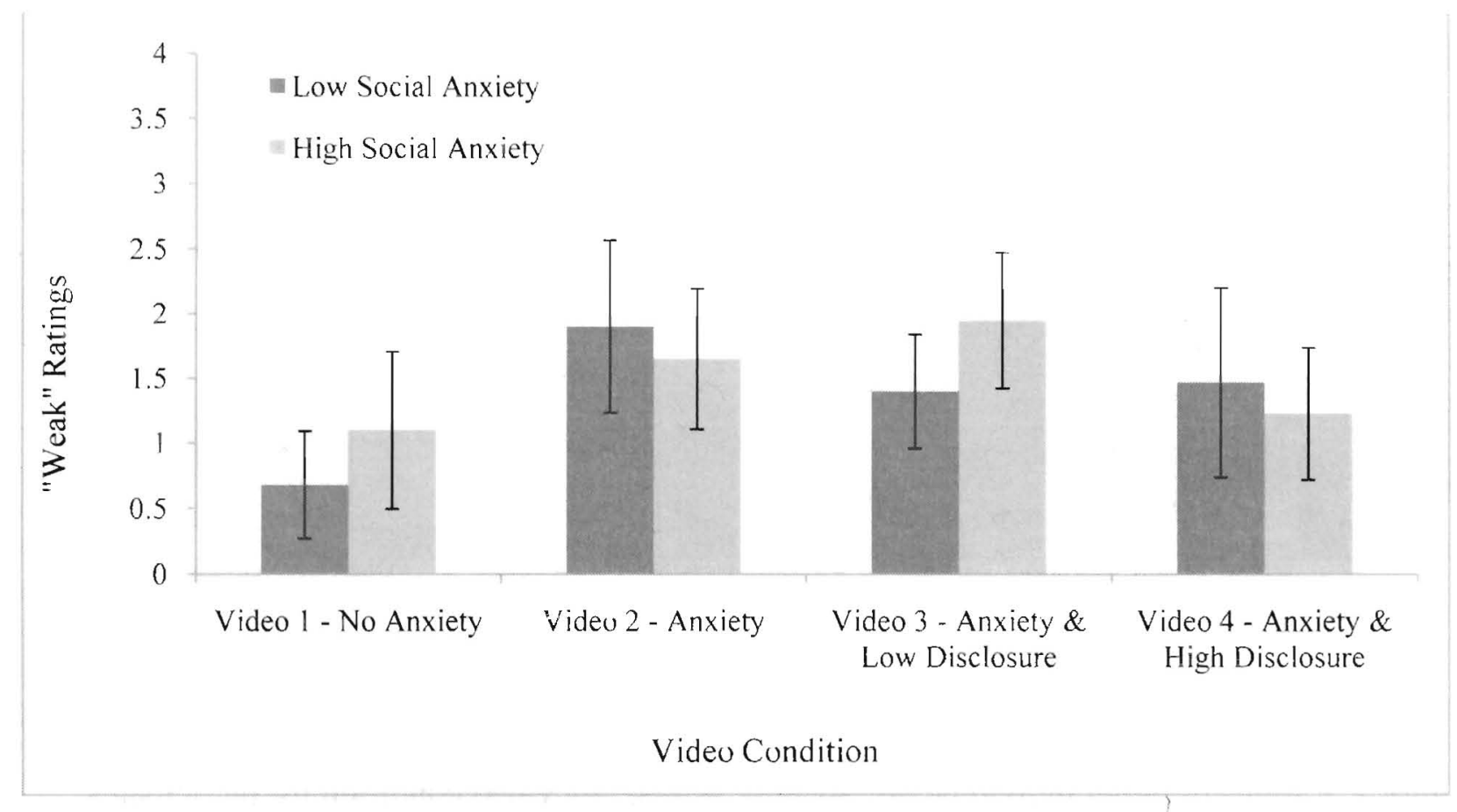

Figure 3. Ratings of target individual on "weak" by video condition for participants low and high in social anxiety. Standard errors are represented in the figure by the error bars attached to each data point. 


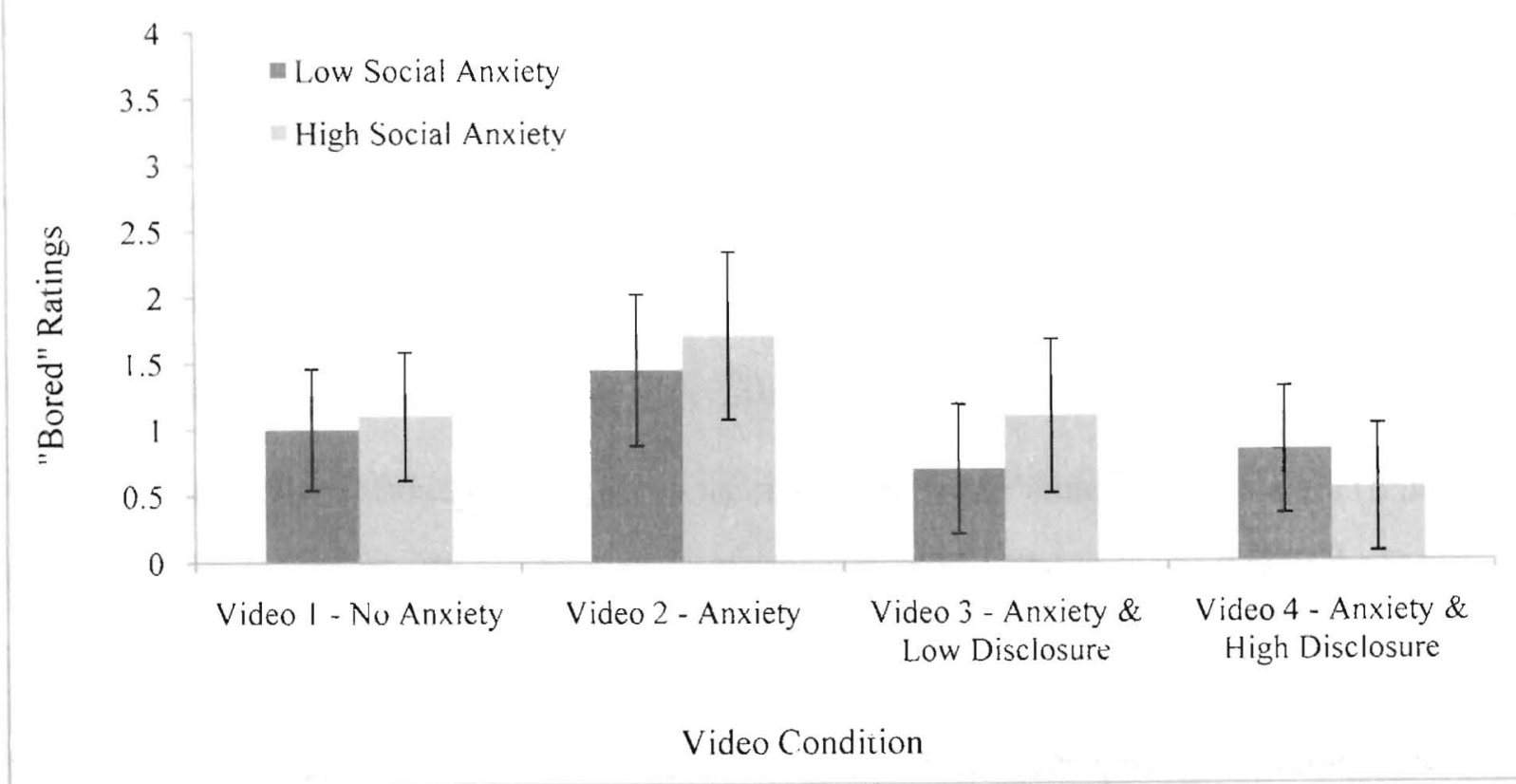

Figure 4. Ratings of target individual on "bored" by video condition for participants low and high in social anxiety. Standard errors are represented in the figure by the error bars attached to each data point. 
Hypothesis 4 stated that perceived similarity on anxiety between the participant and the target individual would mediate the relationship between the participants' level of social anxiety and their ratings of the target individual. According to Baron and Kenny's causal steps approach (1986), mediation would exist if all of the following criteria for establishing mediation were met: i) level of participants' social anxiety must be significantly correlated with ratings of the target individual, ii) level of participants' social anxiety must be significantly correlated with perceived similarity, iii) perceived similarity must be significantly correlated with ratings of the target individual, holding constant any direct effect of level of participants' social anxiety on ratings, and iv) when controlling for perceived similarity on ratings of the target individual, level of participants' social anxiety must no longer be significantly correlated with ratings. However, the level of participants' social anxiety was not significantly correlated with any of the ratings, hence criteria (i) was not satisfied, and the mediational analysis could not be conducted. Secondly, one assumption of a mediational analysis is that the mediator is not caused by the dependent variables (Baron \& Kenny, 1986). However, participants in the current study completed the ratings of perceived similarity after they had rated the target individual, which is problematic as we cannot be sure that the ratings of the target individual (the dependent variable) did not influence ratings of perceived similarity (the possible mediator). Therefore, only the correlations between perceived similarity on anxiety and ratings of the target individual are presented. When the target individual showed signs of anxiety but did not disclose her anxiety (video 2 ), correlations between perceived similarity and ratings were as follows: intelligent $(r=.53, p<.01)$, interesting $(r=.49, p<.01)$, socially skilled $(r=.48, p<.01)$, weak $(r=-.47, p<.01)$, and attractive $(r=.42, p<.05)$. When the target individual showed signs of anxiety and disclosed her anxiety at a high level (video 4), there was a significant correlation between perceived similarity and 
ratings of "attractive" $(r=.38, p<.05)$. No other significant correlations were found for the other video conditions. Thus, there appears to be a relationship between the participants' perceived similarity to the target individual on anxiety and their ratings of the anxious individual.

On the Reasons for Ratings Measure, participants were asked to indicate which two factors influenced their ratings the most, with the options of: physical appearance, body language, signs of anxiety (if applicable), statement that she felt nervous (if applicable), signs of mood, and conversation topic. Of the participants who viewed the video in which the target individual showed signs of anxiety and did not disclose her nervousness (video 2), 91.4\% of participants indicated that the target individual's signs of anxiety influenced their ratings the most, and $85.0 \%$ of participants indicated that her body language influenced their ratings the most. Of the participants who viewed the videos in which the target individual showed signs of anxiety and disclosed her nervousness (videos 3 and 4 ), $73.5 \%$ of participants indicated that the target individual's signs of anxiety influenced their ratings the most, $70.4 \%$ of participants indicated that her body language influenced their ratings the most, and $37.0 \%$ of participants indicated that her statement of nervousness influenced their ratings the most. In contrast, participants who viewed the video in which the target individual did not display signs of anxiety (video 1), $65.2 \%$ of participants indicated that her body language influenced their ratings the most, $56.9 \%$ indicated that the conversation topic influenced their ratings the most, and $38.3 \%$ of participants indicated that her signs of mood influenced their ratings the most. Additionally, participants were asked whether the target individual's body language, signs of anxiety, and statement that she felt nervous, influenced their ratings in a negative or positive direction, or had no effect on their ratings. A chi-square test revealed that a greater frequency of participants who viewed the video in which the target individual appeared anxious (videos 2, 3, and 4) indicated 
that the target individual's body language made the participant think more negatively of the target individual, in comparison to participants who viewed the video in which the target individual did not look anxious (video 1 ), $\chi^{2}(3)=8.31, p<.05$. Table 4 displays the frequency and direction of responses for each factor by video condition.

Comparisons between the Reasons for Ratings Measure and the Perception Rating Measure revealed the accuracy to which participants were able to indicate which factors influenced their ratings of the target individual. Table 5 shows the correlations between the reasons for ratings factors and each of the dependent variables, separated by video condition. The correlations indicate that participants were able to accurately identify which factors contributed to their ratings, but only to a limited degree. 
Table 4

Frequency of Participants Reporting Negative, Positive, or No Change in how Factors Affected their Ratings, separated by Video Condition

\begin{tabular}{lccccc}
\hline Factor & $\begin{array}{c}\text { How Factor } \\
\text { Affected } \\
\text { Ratings }\end{array}$ & $\begin{array}{c}\text { Video } 1 \\
(n=40)\end{array}$ & $\begin{array}{c}\text { Video } 2 \\
(n=41)\end{array}$ & $\begin{array}{c}\text { Video } 3 \\
(n=40)\end{array}$ & $\begin{array}{c}\text { Video } 4 \\
(n=42)\end{array}$ \\
\hline Body language & Negative & $18(45.0 \%)$ & $35(85.4 \%)$ & $37(92.5 \%)$ & $38(90.4 \%)$ \\
& No Change & $11(27.5 \%)$ & $4(9.8 \%)$ & $2(5.0 \%)$ & $3(7.1 \%)$ \\
Pigns of anxiety & Negative & N/A & $37(90.2 \%)$ & $35(87.5 \%)$ & $37(88.1 \%)$ \\
& No Change & N/A & $3(7.3 \%)$ & $3(7.5 \%)$ & $3(7.1 \%)$ \\
Ptatement of & Nesitive & N/A & $1(2.4 \%)$ & $2(5.0 \%)$ & $2(4.8 \%)$ \\
nervousness & No Change & N/A & N/A & $3(7.5 \%)$ & $5(11.9 \%)$ \\
& Positive & N/A & N/A & $12(30 \%)$ & $16(38.0 \%)$ \\
\hline
\end{tabular}

Note. Video 1 - target individual does not appear anxious (and does not disclose her anxiety),

Video 2 - target individual appears anxious and does not disclose her anxiety,

Video 3 - target individual appears anxious and discloses her anxiety at a low level,

Video 4 - target individual appears anxious and discloses her anxiety at a high level. 
Table 5

Correlations between Reasons for Ratings Measure and Perception Rating Measure, separated by Video Condition

\begin{tabular}{|c|c|c|c|c|c|}
\hline $\begin{array}{l}\text { Reasons for } \\
\text { Ratings Factors }\end{array}$ & $\begin{array}{c}\text { Perception } \\
\text { Rating } \\
\text { Characteristics }\end{array}$ & $\begin{array}{l}\text { Video } 1 \\
(n=40)\end{array}$ & $\begin{array}{l}\text { Video } 2 \\
(n=41)\end{array}$ & $\begin{array}{l}\text { Video } 3 \\
(n=40)\end{array}$ & $\begin{array}{c}\text { Video } 4 \\
(n=42)\end{array}$ \\
\hline \multirow[t]{9}{*}{ Body language } & Intelligent & .16 & $.54 * *$ & $.47 * *$ & .11 \\
\hline & Worthless & -.15 & -.21 & -.10 & -.13 \\
\hline & Interesting & $.54 * *$ & $.49^{* *}$ & -.09 & $.44^{* *}$ \\
\hline & Awkward & -.27 & $-.46^{* *}$ & -.31 & $-.48 * *$ \\
\hline & Socially skilled & $.35 *$ & $.42 * *$ & .25 & .26 \\
\hline & Weak & $-.40^{*}$ & -.32 & -.30 & $-.32 *$ \\
\hline & Attractive & .13 & $.32^{*}$ & .30 & -.11 \\
\hline & Bored & $-.57 * *$ & -.31 & -.22 & -.18 \\
\hline & & & & $?$ & \\
\hline \multirow[t]{8}{*}{ Signs of anxiety } & Intelligent & N/A & $.39^{*}$ & $.46^{* *}$ & .11 \\
\hline & Worthless & N/A & -.17 & -.23 & -.11 \\
\hline & Interesting & $N / A$ & .26 & .13 & $.41^{* *}$ \\
\hline & Awkward & $\mathrm{N} / \mathrm{A}$ & -.21 & -.27 & $-.41 * *$ \\
\hline & Socially skilled & $N / A$ & .25 & .10 & $.33 *$ \\
\hline & Weak & N/A & -.26 & -.09 & -.17 \\
\hline & Attractive & N/A & .15 & $.39^{*}$ & -.12 \\
\hline & Bored & $N / A$ & -.04 & -.30 & -.16 \\
\hline \multirow{8}{*}{$\begin{array}{l}\text { Statement of } \\
\text { nervousness }\end{array}$} & Intelligent & N/A & N/A & $.36^{*}$ & .26 \\
\hline & Worthless & N/A & N/A & -.26 & -.19 \\
\hline & Interesting & $N / A$ & $\mathrm{~N} / \mathrm{A}$ & -.09 & $.55^{* *}$ \\
\hline & Awkward & N/A & $\mathrm{N} / \mathrm{A}$ & -.23 & .02 \\
\hline & Socially skilled & N/A & N/A & -.07 & -.04 \\
\hline & Weak & $N / A$ & N/A & .03 & -.25 \\
\hline & Attractive & N/A & $N / A$ & .15 & .28 \\
\hline & Bored & $N / A$ & N/A & $-.32 *$ & .02 \\
\hline
\end{tabular}

Note. Video 1 - target individual does not appear anxious (and does not disclose her anxiety),

Video 2 - target individual appears anxious and does not disclose her anxiety,

Video 3 - target individual appears anxious and discloses her anxiety at a low level,

Video 4 - target individual appears anxious and discloses her anxiety at a high level.

Note. The Reasons for Ratings Measure is scored on a Likert scale ranging from 1 [target individual's (factor X) made me think much more negatively of her] to 5 [target individual's (factor X) made me think much more positively of her], with 3 being [target individual's (factor X) had no effect on my rating]. Thus, a higher correlation between the Reasons for Ratings factors and Perception Rating characteristics would indicate a greater relationship between how the participants thought the factor affected their ratings and whether it actually did.

${ }^{*} p<.05,{ }^{* *} p<.01$ 


\section{Discussion}

The primary goal of the current study was to determine how people respond to others who show and disclose their anxiety, which is important because people with social anxiety disorder often attempt to hide their anxiety symptoms for fear of being judged negatively (Clark \& Wells, 1995; Scholing \& Emmelkamp, 1993), and the extent to which this fear is realistic is unknown. The findings indicated that people, regardless of their own level of social anxiety, judge others who appear anxious negatively on some characteristics, but not others.

Additionally, when the individual appears anxious, the disclosure of anxiety seems to alleviate these negative judgements for the characteristics of "weak" and "bored."

Consistent with Hypothesis 1, participants low and high in social anxiety who watched the video in which the target individual appeared anxious rated her as more awkward, less socially skilled, and more weak than participants who watched the video in which the target individual did not appear anxious. The effect sizes for these findings were either "large" or "approaching large," according to Cohen's guidelines (Cohen, 1988). However, contrary to Hypothesis 1, ratings of "intelligent," "worthless," "interesting," "attractive," and "bored" did not vary as a function of video condition.

Three competing predictions were proposed in regard to how participants, regardless of their level of anxiety, would rate others who disclosed feeling anxious. Support was found for the hypothesis that anticipated that the individual who appeared anxious and disclosed her anxiety would be rated more positively by all participants, in comparison to the individual who was visibly anxious but did not disclose her anxiety. Participants did not rate the individual who appeared anxious and disclosed her anxiety at a high level more negatively on the characteristic of "weak," as they did when the target individual appeared anxious and either did not disclose 
her anxiety, or disclosed it at a low level. As well, participants rated the target individual as looking less bored when she displayed signs of anxiety and disclosed at either a low or high level, in comparison to when she displayed signs of anxiety but did not disclose. Hence, it appears that the disclosure of anxiety can help to alleviate some of the negative judgements by others that stem from showing anxiety symptoms.

No support was found for Hypothesis $2 b$, which anticipated that participants who watched the video in which the anxious individual made a high level disclosure of anxiety would rate her more negatively than the participants who watched the video in which the anxious individual made a low disclosure of anxiety. In fact, the opposite was found for ratings of the characteristic of "weak," whereby a high level of disclosure led to less negative ratings in comparison to signs of anxiety with no disclosure, whereas a low level of disclosure did not lead to less negative ratings.

Contrary to Hypothesis 3, participants who were high in social anxiety rated the target individual who appeared anxious or disclosed her anxiety neither more nor less negatively than participants who were low in social anxiety. Thus, participants' own level of social anxiety did not have an effect on the judgements of others who appeared anxious or disclosed their anxiety. Hypothesis 4, which anticipated that perceived similarity would mediate the relationship between the participants' level of social anxiety and their ratings of the target individual, could not be tested since a relationship between participants' level of social anxiety and ratings of the target individual was not found.

However, significant correlations between perceived similarity on anxiety and participants' ratings of the target individual were found for video 2 (whereby the target individual showed signs of anxiety but did not disclose her anxiety) on the characteristics of 
"intelligent," "interesting," "socially skilled," "weak," and "attractive." Additionally, a significant correlation was also found for video 4 (whereby the target individual showed signs of anxiety and disclosed her anxiety at a high level) on the characteristic of "attractive." Thus, it appears that the more similar participants felt to the target individual on the dimension of anxiety, the more positively (or less negatively) they rated the target individual, and vice versa. This finding was primarily evident in video 2 , when the target individual appeared anxious but did not disclose her anxiety. It is possible that this finding predominantly emerged in this video condition because it depicted a situation with which participants were most able to identify, as perhaps they could relate to looking anxious but not to disclosing their anxiety, in a first-time meeting situation. Hence, actual similarity on anxiety between the participants and the target individual was not significantly correlated with ratings of the target individual, but perceived similarity on anxiety was.

\section{Consistency with Past Literature}

The finding that there is negative evaluation of individuals who appear anxious on some characteristics but not others are in line with the findings by Purdon and colleagues (2001) and Papsdorf and Alden (1998). However, contrary to the findings by Purdon and colleagues, the present study did not find that participants high in social anxiety were more likely to give the individual appearing anxious more negative ratings. The difference in findings between the two studies may be due to the different methodologies used, whereby the current study used videotapes, whereas the study by Purdon et al. (2001) had participants predict the reaction of a colleague to the target individual, using written vignettes. Although the mediational analysis could not be performed, the participants' perceived similarity to the target individual on anxiety was significantly correlated with participants ${ }^{7}$ ratings of the anxious target individual on 
numerous characteristics, which was similar to the results of Papsdorf and Alden (1998), which found that perceived similarity mediated the relationship between social anxiety and social rejection. Hence, there is preliminary evidence to show that the extent to which people feel they are similar to another individual, both in general and on the characteristic of anxiety, can affect their judgements of the person.

The study results indicated that when the target individual showed signs of anxiety, disclosure of the anxiety alleviated some of the negative ratings from participants low and high in social anxiety, on the characteristics of "weak" and "bored." It is possible that these less negative ratings were due to the increased reciprocal self-disclosure among the conversation partners, as found by Meleshko and Alden (1993); however, this requires further empirical testing. The results of the current study were not consistent with findings by Cozby (1972), who found a curvilinear relationship between disclosure and likeability, whereby the highest likeability ratings were found with a moderately intimate disclosure, and the lowest likeability ratings with an extremely low or high disclosure. In the present study, a high level disclosure of anxiety led to less negative ratings compared to a low level disclosure on the characteristic of "weak." Inconsistencies between this study and that by Cozby may have emerged due to differing operational definitions of what constitutes a "high" and "low" level of disclosure. An alternative explanation for the inconsistent findings is the difference in the dependent variables between the two studies, as the participants in the current study rated the target individual specifically on the characteristic of "weak" (among other characteristics), as opposed to likeability, as was used in the study by Cozby (1972). However, more research is needed before conclusions can be made regarding how the level of disclosure of anxiety affects judgements from others. 


\section{Theories Explaining the Negative Judgements of Others}

Overall, it appears that all participants, regardless of their level of social anxiety, seem to judge others who display anxiety symptoms quite negatively. The social psychology theories of correspondence bias, illusory superiority, and just-world phenomenon may be helpful in explaining why people tend to judge others so harshly. Correspondence bias, which is often used interchangeably with the term "fundamental attribution error," is the tendency to draw dispositional inferences from observed behaviour, without taking into account situational factors (Gilbert \& Malone, 1995; Ross, 1977). This phenomenon is most apparent when people try to explain the behaviours of others, but not when explaining their own behaviour, which is known as the actor-observer bias. Gilbert and Malone (1995) have suggested possible reasons for this correspondence bias, including: observers may not be aware of the situational constraints, observers may underestimate the power of the situation, and observers may assume that the situation appears to the other person the same way it appears to themselves. In this study, participants may have been making judgements about the personality traits of the target individual, based on her anxiety symptoms, without considering situational factors that may have played a role in her behaviour.

1llusory superiority, or the better-than-average effect, is the tendency for people to believe that they are better than the average individual in domains that are important to their selfesteem, including personality traits (e.g., Alicke, 1985). Suls and colleagues (2002) found that when participants compared themselves to their friends and peers on various positive traits (e.g., punctuality) and negative traits (e.g., inconsistency), participants rated themselves as most favourable, followed by their friends, and then peers. The majority of studies examining illusory superiority use a direct comparison method, which involves the participant rating themselves and 
an average peer on the same scale. When making these comparisons, it is possible that individuals may be overestimating themselves, underestimating the average peer, or a combination of both. Therefore, in this study when participants were asked to make judgements about the stranger in the video, they may have underestimated her positive qualities, resulting in more negative ratings.

The just-world phenomenon is the strong tendency for people to want to believe that the world is a just place, and consequently view injustices as the fault of the victim, in order to maintain this belief and decrease feelings of vulnerability (Lerner, 1980). A study by Lerner (1966) found that women who witnessed another woman who appeared to receive painful electric shocks while completing a memory task rejected and devalued the victim, and rated her as less physically attractive than participants who did not see the woman receive the shocks. By extension, it is possible that participants rated the target individual who displayed signs of anxiety more negatively, as they blamed her for this fate, as she was more awkward, less socially skilled, and more weak.

\section{Methodological Strengths}

One of the study strengths is that the internal validity was relatively high, since the videotaped conversations were almost identical, with the exception of the anxiety symptoms and disclosure of anxiety manipulation. Thus, factors such as conversation topic, mood, and so forth, were controlled for. As mentioned previously, videotaped interactions are more realistic than using written vignettes, yet provide greater consistency across participants during the study as there is less variation due to differences in the conversations and behaviours of the confederates. Another strength is that the dependent variables included characteristics with which people with social anxiety fear being labelled. This allowed the study to specifically address the accuracy of 
the specific fears of individuals who are high in social anxiety. As well, ratings of the target individual were completed by the participants, instead of by only one or two independent assessors, allowing for a more representative sample of the population. Finally, the cutoff scores were determined using a large undergraduate sample, and the choice to use the top and bottom quartile allowed for sampling from the extremes of the social anxiety spectrum.

\section{Limitations and Future Directions}

One limitation of the study is that the responses on several of the dependent variables were found to be positively skewed, with ratings primarily being between 0 (not at all) to 2 (moderately). A restricted range of responses can decrease the size of the correlation coefficients, since there is little variability in responses. Another limitation is that the generalizability of the study is somewhat limited, as videotaped conversations were used, as opposed to actual social interactions. It may be that using videotaped conversations did not allow the participant to be fully immersed in the conversation. Although participants were instructed to imagine themselves as the conversation partner, and the majority of participants reported being able to do so, this likely was not as effective as having the participants actually participate in the conversation themselves. As well, the videotapes may have been too short to elicit strong feelings of perceived similarity or other factors that may have then led to differences in ratings between the high and low social anxiety conditions. As videotapes may not capture the interpersonal processes that occur during live interactions, future studies could use confederates to interact with the participants. Additionally, the interaction used in the current study was of a first-time meeting situation, and involved two women. Future studies should examine other interactions, such as those with family, friends, partners, and acquaintances, as 
well as use interaction partners of different genders, in order to increase the external validity of the findings.

According to the manipulation check, participants rated the target individual who displayed signs of anxiety as appearing significantly more anxious, but also rated her as appearing significantly more sad, and it is thus possible that it was not the signs of anxiety that lead to the negative ratings per se, but rather a sad or distressed appearance. Future studies should try to control for this confound, however, it may be that signs of anxiety are likely to be accompanied by a more sad or distressed demeanor, especially as depression is often comorbid with social anxiety disorder.

With respect to the participants, a nonclinical, undergraduate and community sample was included, which limits generalizability to other samples. It would be beneficial to conduct the study using a clinical sample, with participants who have a diagnosis of social anxiety disorder. It is possible that significant differences between ratings of others who look and disclose anxiety among individuals with and without social anxiety disorder may emerge. As well, the sample consisted of only $18.5 \%$ males, hence the results of the study may not generalize to the male population. Another limitation is that the current study used the cutoff values on the SIAS obtained from the undergraduate sample for both the undergraduate and community participants. Future studies should strive to obtain cutoff values with all of the samples used in the study. An additional limitation is that when participants were probed as to the nature of the study, it was found that a few participants $(6.7 \%)$ guessed that the study was about judging others who looked anxious in an interaction situation, and it is possible that this may have influenced participants' 
responses. However, when these participants were excluded from the analyses, the majority of the findings remained the same. ${ }^{3}$

The current study examined ratings on the characteristics with which individuals with social anxiety disorder fear being labelled, however, it would also be informative to examine likeability ratings. Although this study found that people judge others who show signs of anxiety negatively on certain characteristics, it is possible that participants may still rate them as likeable and desire future interactions with them. Future studies would benefit from including a likeability measure as a dependent variable. It is also important to note that participants were asked to make ratings of the target individual on the specific characteristics, so it is possible that they would not have evaluated them in these ways, if not explicitly asked to do so. A final limitation is that perceived similarity was measured using only one question, and the validity and reliability of the measure would likely be increased by adding additional questions.

As there is now growing evidence that anxiety symptoms do in fact contribute to some negative judgements from others, it would be useful to determine which other factors also play a role, especially those which are amenable to change. For example, the use of safety behaviours and possible social skills deficits of individuals with social anxiety disorder could be examined as factors that may contribute to negative judgements from others. It would also be helpful to investigate how these factors, as well as the resulting negative perceptions, impact the relationships of individuals with social anxiety disorder.

\footnotetext{
${ }^{3}$ When the participants who guessed the study's purpose were removed from the dataset, the only finding to change was that the difference between video 2 and 3 on the characteristic of "bored" was no longer significant. Thus, participants who watched the video in which the target individual appeared anxious but did not disclose were not rated as appearing more bored than participants who watched the video in which the target individual appeared anxious and disclosed her anxiety at a low level. However, the finding that the disclosure of anxiety at a high level when the individual appeared anxious led to less negative ratings on the characteristics of "bored" remained significant.
} 


\section{Implications}

This study provided some insight to the question of whether people with social anxiety disorder hold an accurate concern of being judged negatively due to their anxiety symptoms, and whether their attempts to hide these signs of anxiety to avoid these judgements are in vain. As the current study found that this is an accurate concern to some degree, therapists should be careful not to assure their clients that other people are not judging their anxiety symptoms, as this may be the case. At the same time, the study found that showing signs of anxiety do not lead to negative judgements on many qualities, including "intelligent," "worthless," "interesting," "attractive," and "bored." If this finding is replicated, it can be of some comfort to clients with social anxiety disorder. Individuals with social anxiety disorder may overestimate the extent to which their anxiety symptoms are visible to others, the degree to which negative judgements from others are occurring due to their signs of anxiety, and the consequences of these judgements. Hence, the study findings can help therapists choose the best approach when working with clients to challenge the clients' beliefs about people's perceptions of their anxiety, what it means if they are judged, and whether they will be able to cope.

As there is some negative evaluation of anxiety symptoms, therapists may want to focus on helping the client to decatastrophise the consequences and costs of being judged negatively based on their signs of anxiety, rather than focusing on other strategies to challenge beliefs, such as looking for evidence for and against the automatic thought. Targeting the cognitive bias of probability overestimation may be useful if the client is overestimating the extent to which these negative judgements are occurring. As participants in the present study indicated that they thought the body language of anxious individuals made them think more negatively of the latter, the skill of positive or open body language can be worked on in treatment. Additionally, it may 
be helpful for therapists to inform clients who notice they are being judged negatively that it is a common phenomenon for individuals who are anxious or depressed (or even actresses pretending to be anxious) to be perceived negatively by others, and thus it is not necessarily due to their specific personality. The successful implementation of these techniques may indirectly lead to a decrease in the clients' anxiety symptoms. However, it is important to note that the implications of the study's findings for use in therapy are only speculative, and treatment studies using a clinical sample are necessary in order to validate these recommendations.

Taylor and Alden (2008) found that group interpersonal cognitive behavioural therapy (ICBT) led to reductions in the clients' estimates of how likely it was that others would respond negatively to them (interpersonal probability), the consequences of them doing so (interpersonal cost), and the importance of interpersonal feedback on their self-evaluation. These changes in cognitive biases were found to be associated with improved treatment outcome. Since the current study found that people do in fact judge others who display anxiety negatively on certain characteristics, it underlines the importance of targeting the interpersonal cost bias of others judging them negatively (instead of focusing primarily on generating evidence for and against the idea that others are making negative judgements), when challenging the belief that others are making negative judgements due to an individual's anxiety symptoms. Lastly, this study provided some insight as to why people high in social anxiety are perceived more negatively by others, with the finding that anxiety symptoms do play a role.

\section{General Conclusions}

Findings from the present study suggest that the fears of individuals with social anxiety disorder are valid to a certain extent, as it was found that people who show signs of anxiety may be judged as more awkward, less socially skilled, and more weak. However, findings suggest 
that they may not be judged any differently on the characteristics of "intelligent," "worthless," "interesting," "attractive," and "bored." When an individual appears anxious, the subsequent disclosure of anxiety seems to alleviate these negative judgements on the characteristics of "weak" and "bored." Ratings by individuals high versus low in social anxiety do not appear to differ substantially. The findings of the current study may be beneficial in informing therapists about cognitive restructuring work with individuals with social anxiety. Future studies should explore this phenomenon using a more realistic interaction paradigm, as well as examine how these negative perceptions impact the relationships of individuals with social anxiety disorder. 
Appendix A

Perception Rating Measure

Instructions: Please rate the individual on your left, who was wearing a grey $t$-shirt, on the following traits:

$$
\text { Not at all Slightly Moderately Very Extremely }
$$

1. Intelligent

2. Worthless

3. Interesting

4. Awkward

5. Socially skilled

6. Weak

7. Attractive

8. Bored

(i.e., not interested in what the other person was saying)
0

0

0

0

0

0

0

0

1
3

3

3

4

4

4

4

4

4 
Appendix B

Reasons for Ratings Measure

Instructions: We are interested in how the following factors influenced your ratings of the person in the video on your left, who was wearing a grey t-shirt. Please circle the appropriate response (any value from 1 to 5 ) for each of the following questions.

1) Physical appearance

1

Her physical appearance made me think much more

negatively of her
2

Her physical appearance had no effect on my rating
4 5

Her physical appearance made me think much more positively of her

2) Body language (e.g., hand gestures, posture)

1

Her body language made me think much more negatively of her
2 Her body language had no
effect on my rating
4

Her body language made me think much more positively of her

3) Signs of anxiety (e.g., trembling, biting lip, avoiding eye contact) - if you did not notice her signs of anxiety, please circle 3.

1

Her signs of anxiety made me think much more negatively of her
2

$$
\begin{gathered}
\text { Her signs of anxiety had } \\
\text { no effect on my rating }
\end{gathered}
$$

4 5

Her signs of anxiety made me think much more positively of her

4) Statement that she felt nervous (if applicable) - if you did not notice her statement, please circle 3.

1

Her statement made me think much more negatively of her
2

3

Her statement had no

effect on my rating
4

Her statement made me think much more positively of her 
5) Signs of mood (e.g., smiling, frowning) - if you did not notice her signs of mood, please circle 3 .

1

Her signs of mood made me think much more negatively of her
2 Her signs of mood had no
effect on my rating
2
Topic had no effect on my rating

4 Her signs of mood made me think much more positively of her

\section{6) Conversation topic}

\section{1}

Topic made me think much more negatively of her

4 5

Topic made me think much more positively of her

7) What thoughts or beliefs did you have about the person in the video on your left, who was wearing a grey $\mathrm{t}$-shirt?

8) Which 2 factors influenced your ratings the most (please circle 2 factors)?
a) Physical appearance
b) Body language
c) Signs of anxiety
d) Statement that she felt nervous
e) Signs of mood
f) Conversation topic 
9) How similar are you to the person in the video on your left (who was wearing the grey t-shirt) in terms of your level of anxiety in social situations? I am:

$\begin{array}{ccccccc}1 & 2 & 3 & 4 & 5 & 6 & 7 \\ \text { Very dissimilar } & & & & & & \text { Very similar }\end{array}$

10) In social situations, do you think you are more or less anxious than the individual in the video on your left (who was wearing the grey t-shirt):

$\begin{array}{llllllc}1 & 2 & 3 & 4 & 5 & 6 & 7 \\ \text { Less Anxious } & & & & & & \text { More anxious }\end{array}$


Instructions: Please circle the appropriate response to each of the following questions.

1) How well were you able to imagine yourself in the shoes of the person in the video on your right (wearing a blue dress shirt):

$\begin{array}{ccccc}\text { Not at all } & \text { A little bit } & \text { Somewhat } & \text { Very much } & \text { Extremely } \\ 0 & 1 & 2 & 3 & 4\end{array}$

2) How well were you able to imagine yourself engaging in a conversation with the person in the video on your left (wearing a grey t-shirt):

$\begin{array}{ccccc}\text { Not at all } & \text { A little bit } & \text { Somewhat } & \text { Very much } & \text { Extremely } \\ 0 & 1 & 2 & 3 & 4\end{array}$

3) To what degree did the videotaped conversation seem realistic:

$\begin{array}{ccccc}\text { Not at all } & \text { A little bit } & \text { Somewhat } & \text { Very much } & \text { Extremely } \\ 0 & 1 & 2 & 3 & 4\end{array}$

4) How happy did the person in the video on your left, who was wearing a grey t-shirt, appear?

$\begin{array}{ccccc}\text { Not at all } & \text { A little bit } & \text { Somewhat } & \text { Very much } & \text { Extremely } \\ 0 & 1 & 2 & 3 & 4\end{array}$

5) How sad did the person in the video on your left, who was wearing a grey t-shirt, appear?

$\begin{array}{ccccc}\text { Not at all } & \text { A little bit } & \text { Somewhat } & \text { Very much } & \text { Extremely } \\ 0 & 1 & 2 & 3 & 4\end{array}$

6) How nervous did the person in the video on your left, who was wearing a grey t-shirt, appear?

$\begin{array}{ccccc}\text { Not at all } & \text { A little bit } & \text { Somewhat } & \text { Very much } & \text { Extremely } \\ 0 & 1 & 2 & 3 & 4\end{array}$




\section{Appendix D \\ Informed Consent Agreement \\ Ryerson University}

Title of Study: Thoughts about Everyday Conversations

You are being asked to participate in a research study. Before you give your consent to be a volunteer, it is important that you read the following information and ask as many questions as necessary to be sure you understand what you will be asked to do.

Investigators: Bethany Gee, B.Sc., Graduate Student, Department of Psychology, Ryerson University

Martin M. Antony, Ph.D., Professor, Department of Psychology, Ryerson University

Purpose of the Study: The purpose of this study is to determine how individuals think and feel about everyday conversations.

Description of the Study: The experiment will involve one visit to the Psychology Research and Training Centre at Ryerson University, located at 105 Bond Street, on the second floor. The total time commitment will be approximately 1 hour, however some participants may take longer to complete the study. If you agree to participate, you will view 2 videotaped clips, which are each approximately 2 minutes in length. You will then be asked to answer questions about yourself, as well as questions regarding your impressions of the individuals you viewed in the videotapes. You will then be told about the study in more depth, and will be given an opportunity to ask questions.

This informed consent agreement and all information that you provide will be stored in locked file cabinets at the Psychology Research and Training Centre at Ryerson University. An ID number, as opposed to your name, will be used on all forms you complete, and in all computer files that contain the data you provide during the study. The data you generate while participating in this study will be kept in a locked file cabinet, separate from this consent agreement and any data that identify you. Your confidentiality will be protected to the full extent allowed by law. Only group findings will be reported in publications and presentations arising from this research.

Potential Risks or Discomforts: There is minimal risk involved if you agree to take part in this study. By signing this form, you understand that you may experience some negative emotions when completing the tasks. You have the right to refuse or discontinue participation at any time. If you decide to stop participating, you will still be entitled to compensation for your time. However, we ask that you try to complete the study in its entirety, for the benefit of psychological research.

Potential Benefits of the Study to You or Others: There may be no direct benefits to you for participating in the study. However, you may derive benefit from the self-assessment, as it may increase your awareness of your own emotions and behaviours. You may also develop a better understanding of research methodology and will be providing researchers with valuable insights. 
Voluntary Nature of Participation: Participation in this study is completely voluntary. Your choice of whether to participate will not influence your future relations with Ryerson University. If you decide to participate, you are free to withdraw your consent and to stop your participation at any time without penalty or loss of benefits to which you are allowed. Your right to withdraw your consent also applies to our use of your data. If you decide that you do not want us to keep or analyze data that you have provided during the course of your participation in this study, please feel free to notify us. At any particular point in the study, you may refuse to answer any particular question or stop participation altogether.

Compensation for Participation in the Study: Compensation for Ryerson students enrolled in the Introduction to Psychology course will be 1 course credit.

Questions about the Study: If you have any questions about the research now, please ask. If you have questions about the research later, you may contact Bethany Gee, B.Sc., Graduate Student, Department of Psychology, Ryerson University, 416-979-5000 ext. 2184, bgee@psych.ryerson.ca or Dr. Martin M. Antony, Ph.D., Professor, Department of Psychology, Ryerson University, 416-979-5000 ext. 2631, mantony@psych.ryerson.ca.

If you have questions regarding your rights as a human participant in this study, you may contact Alexander Karabanow, at the Ryerson University Research Ethics Board for information.

Research Ethics Board

c/o Office of the Vice President, Research and Innovation

Ryerson University

350 Victoria Street

Toronto, ON M5B 2K3

416-979-5042

Agreement: Your signature below means that you have read the information in this agreement and have had a chance to ask any questions you have about the Thoughts about Everyday Conversations study. Your signature also means that you agree to participate in the Thoughts about Everyday Conversations study and have been told that you can change your mind at any time. You have been given a copy of this agreement.

You have been told that by signing this consent agreement you are not giving up any of your legal rights.

Name of Participant (please print)

Signature of Participant

Date

Signature of Investigator

Date 
Appendix E

Demographics Questionnaire

Sex:

Female

Male

Age:

Relationship Status (please check one):

$\square$ Single

$\square$ In a steady relationship

$\square$ Married

$\square$ Co-habiting

$\square$ Separated

$\square$ Divorced

$\square$ Widowed

Ethnicity/Cultural Background:

$\square$ Aboriginal (e.g., First Nations, Métis, Inuit)

$\square$ Black/Afro-Caribbean/African

White/European

Hispanic/Latin American

Asian (e.g., South Asian, East Asian, Southeast Asian)

Biracial/multiracial

Other (specify

Are you enrolled in an educational program?

$\square$ Yes

No

If yes, please check one:

$\square$ Community College

$\square$ University

Adult Education/Continuing Education 
Field of Study:

Education Level (please check one):

$\square$ Did not attend High School

$\square$ Some High School

$\square$ Completed High School/High School Equivalency (GED)

$\square$ Some College/University

$\square$ Completed College/University

$\square \quad$ Some Graduate School

$\square$ Completed Graduate School

Employment Status:

$\square$ Not Working

$\square$ Working Part-Time

$\square$ Working Full-Time

If working part-time or full-time, indicate occupation:

Annual Family Income (please check one):

$\square$ Less than $\$ 19,000$

$\square \quad \$ 20,000-\$ 39,999$

$\square \$ 40,000-\$ 59,999$

$\$ 60,000-\$ 79,999$

$\$ 80,000-\$ 99,999$

More than $\$ 100,000$

Don't know

Number of people supported by the family income (including self): 


\section{Appendix F \\ Debriefing Form}

Firstly, this study investigates how people view signs of anxiety in others, how people view anxious individuals telling others about their anxiety, and how one's level of social anxiety affects these perceptions. Determining how people respond to others showing and telling others about their anxiety is important because people who are socially anxious attempt to hide their anxiety symptoms for fear of being judged negatively (Clark \& Wells, 1995), and the extent to which this fear is realistic is unknown. Secondly, this study examines whether the perception ratings are affected by telling others about an emotional state in general (e.g., happiness, sadness), or whether the effect is specific to telling others about anxiety. Thirdly, this study explores how social anxiety is related to: (1) the belief that anxiety-related symptoms (e.g., increased heart rate, dizziness) are harmful, (2) the fear of negative evaluation, (3) embarrassment by others in social situations, and (4) telling others about anxiety in everyday life.

Clark, D.M., \& Wells, A. (1995). A cognitive model of social phobia. In: R.G. Heimberg, M.R. Liebowitz, D.A. Hope, \& F.R. Schneier (Eds.), Social phobia: Diagnosis, assessment and treatment (pp. 69-93). New York: Guilford.

If you are currently experiencing psychological distress and would like to discuss your concerns in a safe and confidential environment, please be aware that the Ryerson Centre for Student Development and Counselling (CSDC) is a free resource located on campus. Staff at the Counselling Centre provides support and guidance for a range of concerns including anxiety, low mood, and academic difficulties. The contact information for the CSDC is as follows:

Centre for Student Development and Counselling

Website: http://www.ryerson.ca/counselling/index.html

Email: csdc@ryerson.ca

Phone: 416-979-5195

Location: JOR-07C (Lower level of Jorgensen Hall. 380 Victoria Street) 


\section{References}

Alden, L.E. (2001). Interpersonal perspectives on social phobia. In R.W. Crozier, \& L.E. Alden (Eds.), International handbook of social anxiety: Concepts, research and interventions relating to the self and shyness (pp. 381-404). New York, NY: John Wiley and Sons.

Alden, L.E., \& Bieling, P. (1998). Interpersonal consequences of the pursuit of safety. Behaviour Research and Therapy, 36, 53-64. doi: 10.1016/S0005-7967(97)00072-7

Alden, L.E., \& Wallace, S.T. (1995). Social phobia and social appraisal in successful and unsuccessful social interactions. Behaviour Research and Therapy, 33, 497-506. doi: $10.1016 / 0005-7967(94) 00088-2$

Alicke, M.D. (1985). Global self-evaluation as determined by the desirability and controllability of trait adjectives. Journal of Personality and Social Psychology, 49, 1621-1630. doi: $10.1037 / 0022-3514.49 .6 .1621$

American Psychiatric Association. (2000). Diagnostic and statistical manual of mental disorders ( $4^{\text {th }}$ ed., text revision). Washington, DC: Author.

Amir, N., Foa, E.B., \& Coles, M.E. (1998). Negative interpretation bias in social phobia. Behaviour Research and Therapy, 36, 945-957. doi: 10.1016/S0005-7967(98)00060-6

Antony, M.M, Coons, M.J., McCabe, R.E., Ashbaugh, A.R., \& Swinson, R.P. (2006). Psychometric properties of the Social Phobia Inventory: Further evaluation. Behaviour Research and Therapy, 44, 1177-1185. doi: 10.1016/j.brat.2005.08.013

Baker, S.R., \& Edelmann, R.J. (2002). Is social phobia related to lack of social skills? Duration of skill-related behaviours and ratings of behavioural adequacy. British Journal of Clinical Psychology, 41, 243-257. doi: 10.1348/014466502760379118 
Baron, R.M., \& Kenny, D.A. (1986). The moderator-mediator distinction in social psychological research: Conceptual, strategic and statistical considerations. Journal of Personality and Social Psychology, 51, 1173-1182.

Brehm, J.W. (1966). A theory of psychological reactance. San Diego, CA: Academic Press. Brown, C.J., Turovsky, J., Heimberg, R.G., Juster, H.R., \& Barlow, D.H. (1997). Validation of the Social Interaction Anxiety Scale and the Social Phobia Scale across the anxiety disorders. Psychological Assessment, 9, 21-27. doi: 10.1037/1040-3590.9.1.21

Bruch, M.A., Borsky, J.M, Collins, T.M., \& Berger, P.A. (1989). Shyness and sociability reexamined: A multicomponent analysis. Journal of Personality and Social Psychology, 57, 904-915. doi: $10.1037 / 0022-3514.57 .5 .904$

Clark, D.M. (2001). A cognitive perspective on social phobia. In W.R. Crozier, \& L.E. Alden (Eds.), International handbook of social anxiety: Concepts, research and interventions relating to the self and shyness (pp. 405-430). New York, NY: John Wiley and Sons.

Clark, D.M., \& Wells, A. (1995). A cognitive model of social phobia. In: R.G. Heimberg, M.R. Liebowitz, D.A. Hope, \& F.R. Schneier (Eds.), Social phobia: Diagnosis, assessment and treatment (pp. 69-93). New York, NY: Guilford Publications.

Clark, J. V., \& Arkowitz, H. (1975). Social anxiety and self-evaluation of interpersonal performance. Psychological Reports, 36, 211-221.

Cohen, J. (1988). Statistical power analysis for the behavioral sciences $\left(2^{\text {nd }}\right.$ ed.). New York, NY: Academic Press.

Collins, N.L., \& Miller, L.C. (1994). Self-disclosure and liking: A meta-analytic review. Psychological Bulletin, 116, 457-475. 
Connor, K.M., Davidson, J.R.T., Churchill, L.E., Sherwood, A., Foa, E., \& Wesler, R.H. (2000). Psychometric properties of the Social Phobia Inventory (SPIN). British Journal of Psychiatry, 176, 379-286. doi: 10.1192/bjp.176.4.379

Coyne, J.C. (1976). Depression and the response of others. Journal of Abnormal Psychology, 85, 186-193.

Cozby, P.C. (1972). Self-disclosure, reciprocity and liking. Sociometry, 35, 151-160. doi: $10.2307 / 2786555$

Creed, A.T., \& Funder, D.C. (1998). Social anxiety: From the inside and outside. Personality and Individual Differences, 25, 19-33. doi: 10.1016/S0191-8869(98)00037-3

Crowne, D.P., \& Marlowe, D. (1960). A new scale of social desirability independent of psychopathology. Journal of Consulting Psychology, 24, 349-354. doi: $10.1037 / \mathrm{h} 0047358$

Dalto, C.A., Ajzen, I., \& Kaplan, K.J. (1979). Self-disclosure and attraction: Effects of intimacy and desirability on beliefs and attitudes. Journal of Research in Personality, 13, 127-138. doi: $10.1016 / 0092-6566(79) 90025-4$

Del-Ben, C.M., Hallak, J.E., Sponholz, A.Jr., Marques, J.M., Labate, C.M., Contel, J.O., \& Zuardi, A.W. (2005). Accuracy of psychiatric diagnosis performed under indirect supervision. Revista Brasileira de Psiquiatria, 27, 58-62. doi: 10.1590/S151644462005000100013

Derlega, V.J., Harris, M.S., \& Chaikin, A.L. (1973). Self-disclosure reciprocity, liking and the deviant. Journal of Experimental Social Psychology, 9, 277-284. doi: 10.1016/0022$1031(73) 90065-6$ 
First, M.B., Spitzer, R.L., Gibbon, M., \& Williams, J.B.W. (1996). Structured Clinical Interview for DSM-IV Axis I disorders - Patient edition. New York, NY: New York Psychiatric Institute, Biometrics Research Department.

Fydrich, T., Chambless, D.L., Perry, K.J., Buergener, F., \& Beazley, M.B. (1998). Behavioral assessment of social performance: A rating system for social phobia. Behaviour Research and Therapy, 36, 995-1010. doi: 10.1016/S0005-7967(98)00069-2

Gilbert, D.T., \& Malone, P.S. (1995). The correspondence bias. Psychological Bulletin, 117, 2138. doi: $10.1037 / 0033-2909.117 .1 .21$

Heimberg, R.G., Mueller, G.P., Holt, C.S., Hope, D.A., \& Liebowitz, M.R. (1992). Assessment of anxiety in social interaction and being observed by others: The Social Interaction Anxiety Scale and the Social Phobia Scale. Behavior Therapy, 23, 53-73. doi: $10.1177 / 073428290101900105$

Horenstein, D., \& Gilbert, S.J. (1976). Anxiety, likeability, and avoidance as responses to selfdisclosure. Small Group Behavior, 7, 423-432. doi: 10.1177/104649647600700404

Jacobson, N. S., \& Anderson, E. A. (1982). Interpersonal skill and depression in college students: An analysis of the timing of self-disclosures. Behavior Therapy, 13, 271-282. doi: $10.1016 / \mathrm{S} 0005-7894(82) 80037-3$

Jones, W.H., \& Carpenter, B.N. (1986). Shyness, social behavior, and relationships. In W.H. Jones, J.M., Cheeck, \& S. Briggs (Eds.), Shyness: Perspectives on research and treatment (pp. 227-238). New York, NY: Plenum Press.

Jones, W.H., \& Russell, D. (1982). The social reticence scale: An objective instrument to measure shyness. Journal of Personality Assessment, 46, 629-631. doi: 10.1207/s15327752jpa4606_12 
Kleinke, C.L. (1979). Effects of personal evaluations. In (i.J. Chelune (lid.), Silf-divclosure:

Origins, patterns, and implications of openness in interpersomal relationships (p). 5979). San Francisco, CA: Jossey-Bass.

Kohen, J. (1975). Liking and self-disclosure in opposite sex dyads. P'sychological Reports, 36, 695-698.

Lerner, M. (1966). Observer reaction to the 'innocent victim': Compassion or rejection? Journal of Personality and Social Psychology, 4, 203-210. doi: 10.1037/h0023562.

Lerner, M. J. (1980). The belief in a just world: A fundamental delusion. New York, NY: Ilenum Press.

Mattick, R. P., \& Clarke, J. C. (1998). Development and validation of measures of social phobia scrutiny fear and social interaction anxiety. Behaviour Research and Therapy, 36, 455470. doi: $10.1016 / \mathrm{S} 0005-7967(97) 10031-6$

Meleshko, K.G.A., \& Alden, L.E. (1993). Anxiety and self-disclosure: Toward a motivational model. Journal of Personality and Social Psychology, 64, 10000-1009. doi: 10.10.37/(1)223514.64 .6 .1000

Montoya, R.M., Horton, R.S., \& Kirchner, J. (2008). Is actual similarity necessary for attraction? A meta-analysis of actual and perceived similarity. Journal of Social and Personal Relationships, 25, 889-922. doi: 10.1177/0265407508096700)

Papsdorf, M. \& Alden, L. (1998). Mediators of social rejection in social anxiety: Similarity, selfdisclosure, and overt signs of anxiety. Journal of Research in Personality, 32, 351-36\%. doi: 10.1006/jrpe.1998.2219 
Purdon, C., Antony, M.M., Monteiro, S., \& Swinson, R.P. (2001). Social anxiety in college students. Journal of Anxiety Disorders, 15, 203-215. doi: 10.1016/S0887-6185(01)000597

Rapee, R. M., \& Lim, L. (1992). Discrepancy between self- and observer ratings of performance in social phobics. Journal of Abnormal Psychology, 101, 728-731. doi: 10.1037/0021$843 X .101 .4 .728$

Reynolds, W.M. (1982). Development of reliable and valid short forms of the Marlowe-Crowne Social Desirability Scale. Journal of Clinical Psychology, 38, 119-125. doi: 10.1002/1097-4679(198201)38:1<119::AID-JCLP2270380118>3.0.CO;2-I

Rook, K.S., Pietromonaco, P.R., \& Lewis, M.A. (1994). When are dysphoric individuals distressing to others and vice versa? Effects of friendship, similarity, and interaction task. Journal of Personality and Social Psychology, 67, 548-559. doi: 10.1037/00223514.67 .3 .548

Ross, L. (1977). The intuitive psychologist and his shortcomings: Distortions in the attribution process. In L. Berkowitz (Ed.), Advances in experimental social psychology (vol. 10, pp. 173-220). New York, NY: Academic Press.

Salkovskis, P.M. (1991). The importance of behaviour in the maintenance of anxiety and panic: A cognitive account. Behavioural Psychotherapy, 19, 6-19. doi: $10.1017 / \mathrm{S} 0141347300011472$

Scholing, A., \& Emmelkamp, P.M.G. (1993). Cognitive and behavioural treatments of fear of blushing, sweating or trembling. Behaviour Research and Therapy, 31, 155-170. doi: $10.1016 / 0005-7967(93) 90067-5$ 
Stevick, R.A. (1979). The effect of incompetence in self-disclosure on interpersonal attraction. Unpublished doctoral dissertation, Texas Tech University, Lubbock, TX.

Suls, J., Lemos, K., \& Stewart, H.L. (2002). Self-esteem, construal, and comparisons with the self, friends and peers. Journal of Personality and Social Psychology, 82, 252-261. doi: $10.1037 / 0022-3514.82 .2 .252$

Taylor, C.T., \& Alden, L.E. (2008). Self-related and interpersonal judgment biases in social anxiety disorder: Changes during treatment and relationship to outcome. International Journal of Cognitive Therapy, 1, 125-137.

VandenBos, G.R. (2006). APA dictionary of psychology. Washington, DC: American Psychological Association.

Voncken, M.J., Alden, L.E., \& Bögels, S.M. (2006). Hiding anxiety versus acknowledgment of anxiety in social interaction: Relationship with social anxiety. Behaviour Research and Therapy, 44, 1673-1679. doi: 10.1016/j.brat.2005.11.005

Voncken, M.J., Alden, L.E., Bögels, S.M., \& Roelofs, F. (2008). Social rejection in social anxiety disorder: The role of performance deficits, evoked negative emotions and dissimilarity. The British Psychological Society, 47, 439-450. doi:

\section{$10.1348 / 014466508 \times 334745$}

Zook Ii, A., \& Sipps, G.J. (1985). Cross-validation of a short form of the Marlowe-Crowne Social Desirability Scale. Journal of Clinical Psychology, 41, 236-238. doi: 10.1002/1097-4679(198503)41:2<236::AID-JCLP2270410217>3.0.CO;2-H 